\title{
Electrochemical activation of molecular nitrogen at the Ir/YSZ interface
}

\author{
Ilia Valov, ${ }^{* a}$ Bjoern Luerssen, ${ }^{b}$ Eva Mutoro, $\dagger^{b}$ Luca Gregoratti, ${ }^{c}$ \\ Roger A. De Souza, ${ }^{d}$ Thomas Bredow, ${ }^{e}$ Sebastian Günther, ${ }^{f}$ Alexei Barinov, ${ }^{c}$ \\ Pavel Dudin, ${ }^{c}$ Manfred Martin ${ }^{d}$ and Jürgen Janek ${ }^{* b}$
}

Received 29th June 2010, Accepted 1st November 2010

DOI: $10.1039 / \mathrm{c0cp01024c}$

Nitrogen is often used as an inert background atmosphere in solid state studies of electrode and reaction kinetics, of solid state studies of transport phenomena, and in applications e.g. solid oxide fuel cells (SOFC), sensors and membranes. Thus, chemical and electrochemical reactions of oxides related to or with dinitrogen are not supposed and in general not considered.

We demonstrate by a steady state electrochemical polarisation experiments complemented with in situ photoelectron spectroscopy (XPS) that at a temperature of $450{ }^{\circ} \mathrm{C}$ dinitrogen can be electrochemically activated at the three phase boundary between $\mathrm{N}_{2}$, a metal microelectrode and one of the most widely used solid oxide electrolytes - yttria stabilized zirconia (YSZ) - at potentials more negative than $E=-1.25 \mathrm{~V}$. The process is neither related to a reduction of the electrolyte nor to an adsorption process or a purely chemical reaction but is electrochemical in nature. Only at potentials more negative than $E=-2 \mathrm{~V}$ did new components of $\mathrm{Zr} 3 \mathrm{~d}$ and Y 3d signals with a lower formal charge appear, thus indicating electrochemical reduction of the electrolyte matrix. Theoretical model calculations suggest the presence of anionic intermediates with delocalized electrons at the electrode/electrolyte reaction interface. The ex situ SIMS analysis confirmed that nitrogen is incorporated and migrates into the electrolyte beneath the electrode.

\section{Introduction}

Molecular nitrogen $\ddagger$ is usually considered as an inert gas towards solid oxide materials at temperatures below $800{ }^{\circ} \mathrm{C}$ and in particular in solid state electrochemical studies of SOFC materials. On the other hand nitrogen doped oxides such as $\mathrm{TiO}_{2}: \mathrm{N}, \mathrm{YSZ}: \mathrm{N}$, etc. or oxinitrides such as $\mathrm{TaON}$ have become of significant interest as materials in photovoltaics, ${ }^{1-3}$ as non-toxic pigments, ${ }^{4,5}$ for semiconductor applications ${ }^{6}$ and possible alternative materials for oxide and/or nitrogen ion

${ }^{a}$ Research Center Juelich, Institute for Solid State Research (IFF-6), 52425 Juelich, Germany. E-mail: i.valov@fz-juelich.de;

Fax: + 49246161 2550; Tel: + 492461612994

${ }^{b}$ Institut of Physical Chemistry, Justus-Liebig-University,

Heinrich-Buff-Ring 58, 35392 Giessen, Germany.

E-mail: juergen.janek@phys.chemie.uni-giessen.de;

Fax: + 4964199 34580; Tel: + 496419934500

${ }^{c}$ Sincrotrone Trieste-ELETTRA-S. S. 14 km 163,5, AREA Science

Park, 34012 Basovizza, Trieste, Italy

'Institute of Physical Chemistry, RWTH Aachen University,

52074 Aachen, Germany

${ }^{e}$ Institute of Theoretical Chemistry, University of Bonn,

Wegeler Str. 12, 53115 Bonn, Germany

${ }^{f}$ Department of Chemistry, University of Munich,

Butenandtstr. 5-13 E, 81377 Munich, Germany

$\dagger$ Current address: Electrochemical Energy Laboratory, Massachusetts Institute of Technology, 77 Massachusetts Avenue, Cambridge, MA 02139, USA.

$\ddagger$ For the sake of accuracy we will use "dinitrogen" whenever sensible in the text to accent its molecular form. conducting solid electrolytes. ${ }^{7-9}$ Numerous experimental studies and theoretical calculations have been published in recent years, reporting on the structure and transport properties of nitrogen doped oxides. ${ }^{8-17}$ Nitrogen doping (assuming a trivalent negative oxidation state for the nitrogen ions) introduces into the oxide sublattice an additional relative negative charge. This negative charge can be compensated either by electronic or ionic defects (electron holes or oxygen vacancies). Both possibilities attract interest: the compensation of the negative charge of $\mathrm{N}_{O}^{\prime}$ defects by electron holes is suggested as a way to prepare p-type oxides (e.g. p- $\mathrm{ZnO}$ ). The ionic compensation by oxygen vacancies is studied as a way to design new solid electrolytes. Lerch et al. have reported that substitution of oxide by nitride ions in $\mathrm{ZrO}_{2}$ or $(\mathrm{Zr}, \mathrm{Me}) \mathrm{O}_{2}$ stabilizes the cubic fluorite structure and increases the number of vacancies in initially tetragonal zirconia containing up to $5 \mathrm{~mol} \% \mathrm{Y}_{2} \mathrm{O}_{3}$ as cation dopant. An upper limit for solubility of $2.4 \mathrm{wt} . \%$ nitrogen in zirconia has been determined. ${ }^{15}$ The equilibrium describing the reversible nitrogen incorporation assuming oxygen vacancies as charge compensating defects (in Kröger-Vink notation) is given by:

$$
\mathrm{N}_{2}+3 \mathrm{O}_{\mathrm{O}}^{\times} \rightleftharpoons 2 \mathrm{~N}_{\mathrm{O}}^{\prime}+3 / 2 \mathrm{O}_{2}+\mathrm{V}_{\mathrm{O}}^{\bullet \bullet}
$$

Here, $\mathrm{N}_{\mathrm{O}}^{\prime}$ represents a nitride ion on the oxide sublattice. As the absolute charge number of the nitrogen ions is supposed to be -3 , the relative charge number denoted by the superscript is -1 . 
Comparing the standard free enthalpy of formation of $\mathrm{ZrN}$ and $\mathrm{ZrO}_{2}$ compounds, one finds a much smaller value (less negative) for the nitride, mainly caused by the large binding energy of the nitrogen molecule. Zirconium nitride and oxinitride are metastable phases at room temperature. At higher temperatures and in presence of oxygen the reaction:

$$
\mathrm{ZrN}+\mathrm{O}_{2} \leftrightharpoons \mathrm{ZrO}_{2}+1 / 2 \mathrm{~N}_{2}
$$

has a negative free enthalpy $\left(\Delta_{\mathrm{r}} G^{\circ}=-585 \mathrm{~kJ} \mathrm{~mol}^{-1}\right.$ at $\left.1000 \mathrm{~K}\right)$ and the nitrogen concentration in YSZ is negligibly small in thermodynamic equilibrium under atmospheric conditions. In order to shift the equilibrium in eqn (1) to the right, either a significant decrease of the oxygen activity is required or nonequilibrium techniques have to be applied. Different approaches have been applied to incorporate nitrogen into oxide materials: (i) a thermochemical approach (in the temperature range $1473<T / \mathrm{K}<2673$ ), ${ }^{18}$ (ii) pulsed laser deposition (PLD), ${ }^{19}$ and (iii) an electrochemical approach. ${ }^{20,21}$ The difference between these three methods can be illustrated by decomposing eqn (1) into two reactions:

$$
\mathrm{O}_{2}(\text { gas })+2 \mathrm{~V}_{\mathrm{O}}^{\bullet \bullet}(\mathrm{YSZ})+4 \mathrm{e}^{-} \rightleftharpoons 2 \mathrm{O}_{\mathrm{O}}^{\times}(\mathrm{YSZ})
$$

and

$$
\mathrm{N}_{2}(\text { gas })+2 \mathrm{~V}_{\mathrm{O}}^{\bullet \bullet}(\mathrm{YSZ})+6 \mathrm{e}^{-} \rightleftharpoons 2 \mathrm{~N}_{\mathrm{O}}^{\prime}(\mathrm{YSZ})
$$

In approach (i) the electrons required for reaction (4) to proceed are generated by reaction (3) proceeding towards the left (i.e. low oxygen activities). However, to use eqn (1) as a basis for stoichiometric anion exchange without introducing additional electrons is difficult. At a given pressure $p_{\mathrm{N}_{2}}$ only one specific $p_{\mathrm{O}_{2}}$ will keep the electron concentration constant.

In approach (ii) electrons are supplied mainly from the plasma (non-equilibrium system) but depending on the deposition conditions also by the loss of oxygen according to reaction (3).

In case (iii) the electrons for reaction (4) are directly supplied by the electrode (as is applied in the present paper).

The electrochemical reduction and incorporation of nitrogen into YSZ has the advantage that the activity of oxygen at the electrode/electrolyte interface can be easily controlled by the applied voltage. Even small applied voltages result in a large decrease in the oxygen activity thus shifting the nitrogen equilibrium. An additional advantage is that nitrogen ions can be incorporated locally into the solid electrolyte with a lateral resolution determined by the size of the electrode and the time of reduction.

With $9 \mathrm{eV}$ dissociation energy the nitrogen molecule is extremely difficult to activate i.e. to reduce or oxidise. The first accessible information on an incorporation of nitrogen ions during electrode polarisation into zirconia originates from 1970, where inclusions of $\operatorname{Zr}\left(\mathrm{O}_{y} \mathrm{~N}_{1-y}\right)$ were detected after polarisation in a strongly reducing atmosphere, under high cathodic currents and temperatures of $1673 \mathrm{~K} .{ }^{22}$ The oxinitride formation was interpreted as a result of a chemical reaction between the partially reduced zirconia and nitrogen.

We already reported on the incorporation of nitrogen ions into YSZ forming oxinitrides and suggested a reduction mechanism involving at least two intermediate states with a rate determining step the reaction: ${ }^{20,21} \mathrm{~N}_{2}^{-}+\mathrm{e}^{-} \rightarrow \mathrm{N}_{2}^{2-}$.
Molecular nitrogen anions of the type $\mathrm{N}_{2}{ }^{2-}(z=1-4)$ have been reported and/or calculated to be stable in solids, ${ }^{11,23-25}$ but no direct evidence or study exists that such species are stable at the surface and are involved in the electrochemical reaction at the electrode/electrolyte three phase boundary.

In this paper we report on physico-chemical studies of electrode reactions at the three phase boundary between an iridium micro-electrode and single crystalline yttria stabilized zirconia in ambient nitrogen. In order to support the suggested mechanism of the dinitrogen reduction, we performed simultaneously with the steady state current-voltage measurements an in situ XPS ( $\mu$-ESCA) and ex situ SIMS analysis in order to identify the reaction products and intermediates and also the depth and lateral distribution of the chemical components. The competing electrode reactions of nitrogen and electrolyte reduction were monitored by the chemical shifts of the $\mathrm{N} 1 \mathrm{~s}$, O 1s, Zr 3d and Y 3d XPS signals.

Theoretical calculations of the shifts of the $\mathrm{N} 1 \mathrm{~s}$ binding energy have been performed in order to support the identification of the different nitrogen species we detected. The alteration of the XPS spectra for the other ions i.e. $\mathrm{Zr}^{4+}, \mathrm{Y}^{3+}$ and $\mathrm{O}^{2-}$ as a result of the electrochemical polarization is demonstrated. The lateral and depth distribution of incorporated nitrogen ions was additionally studied by time-of-flight secondary ion mass spectrometry (ToF-SIMS).

The current results constitute the first steps towards a better understanding of the electrochemical reactivity of nitrogen in solid state ionics. Besides the relevance for various applications, the heterogeneous electrochemical kinetics of molecular nitrogen is of fundamental interest for the field of reactivity of solids.

\section{Experimental}

\subsection{Electrochemical cell}

We used single crystals of $9.5 \mathrm{~mol} \%$ yttria stabilised zirconia (9.5YSZ) with (111) orientation as the solid electrolyte. The crystals had a size of $1 \times 1 \mathrm{~cm}$ and thickness of $1 \mathrm{~mm}$ with one side being polished (grade $0.02 \mu \mathrm{m}$ purchased from CrysTec $\mathrm{GmbH})$. On the unpolished complete back side of the crystal a counter electrode was fixed by drying platinum paste at $523 \mathrm{~K}$ for two hours. The working electrode was a tip made of $1 \mathrm{~mm}$ thick iridium wire sharpened by polishing to reach a diameter of approximately $100 \mu \mathrm{m}$ and pressed by a stainless steel spring to the polished side of the single crystal. As the geometrical surface area of the iridium tip was much smaller than the surface area of the counter electrode, the polarization of the counter electrode was negligible and we used it therefore as a reference electrode. For some experiments the crystal was reduced prior to measurements by applying a negative voltage of $E=-2.5 \mathrm{~V}$ to the micro-electrode in UHV conditions.

The samples were mounted in a sample holder with a heating filament (ceramic insulation at the bottom) and electrically connected with the potentiostat. A scheme of the cell arrangement is given in Fig. 1.

Before the XPS measurements, the samples were heated up to $1073 \mathrm{~K}$ in vacuum to remove contaminants. The surfaces of the crystals were analysed by Auger spectroscopy 


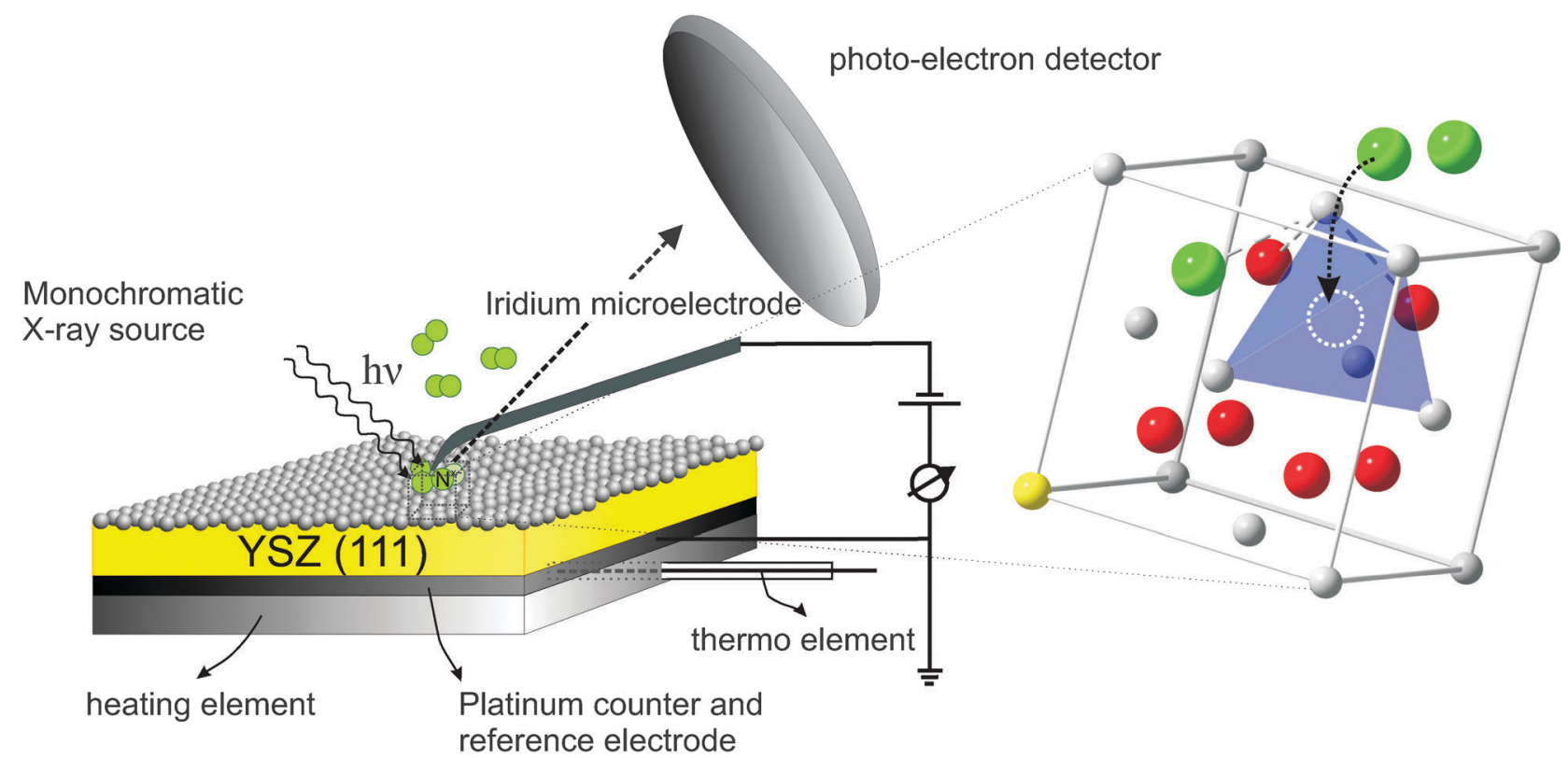

Fig. 1 Scheme of the cell arrangement for electrochemical and XPS experiments. The YSZ unit cell is given in the right corner.

(Perkin Elmer at $2 \mathrm{kV}(\mathrm{Al} \mathrm{K} \alpha)$ of primary energy). If contaminants (e.g. carbon or carbon hydrates) were detected we sputtered the samples with $\mathrm{Ar}^{+}$ions to remove them.

\subsection{Electrochemical experiments}

Cathodic and anodic steady state polarization experiments were performed with micro-electrodes and the steady state current-voltage characteristics were recorded. Simultaneously we collected XPS spectra and SPEM images of the region around the micro-electrode. For each point of the current-voltage characteristics we obtained a complete set of XPS information (N 1s, O 1s, Y 3d and Zr 3d).

As a voltage source a potentiostat/galvanostat (Jaissle IMP 83TC, Jaissle Elektronik GmbH, Weiblingen, Germany) was used; the applied voltage was varied in the range $E=3 \mathrm{~V}$ down to $E=-3 \mathrm{~V}$.

The temperature was kept at $T=723 \mathrm{~K}$ measured at the upper side of the heating filament and was kept constant during the experiments (max. deviation of $\pm 2 \mathrm{~K}$ at the sample surface). The nitrogen partial pressure in the XPS-chamber was kept at $p=10^{-5} \mathrm{~Pa}$, unless otherwise stated.

\subsection{In situ XPS and SPEM}

All electrochemical, in situ XPS and SPEM measurements were performed at the synchrotron ELETTRA in Trieste, Italy. The photon energy of the incoming X-ray beam is $640.0 \mathrm{eV}$ and the overall energy resolution of the analyzer was better than $0.5 \mathrm{eV}$, sufficient to monitor energy shifts of $0.1 \mathrm{eV}$. The XPS spectra were acquired with a PHOIBOS 100 from SPECS equipped with a 48-channels electron detector. The X-ray beam allows a spatial resolution of below $100 \mathrm{~nm}$.

The shift of the XPS spectra due to a polarization of the samples was accounted by monitoring the Ir $4 \mathrm{f}$ peak on iridium particles ( $\mathrm{Au} 4 \mathrm{f}$ on deposited gold spots) at the electrolyte surface without mechanical contact to the microelectrode.
The data from the recorded XPS spectra were analyzed and evaluated with the FitXPS2 peak-fitting software, ${ }^{26}$ which fits Doniach-Sunjic peak profiles ${ }^{27}$ convoluted by Gaussians.

\subsection{Theoretical calculations}

The $\mathrm{N}$ 1s photo-ionization energies of molecular nitrogen and possible anionic surface species during the electrochemical reduction were calculated with two quantum-chemical methods. The basic assumption of our model calculations is that $\mathrm{N}_{2}$ molecules and ions only weakly interact with the surface, so that the core levels are not significantly perturbed with respect to the gas phase. In a previous theoretical study ${ }^{28}$ it was shown that dinitrogen is indeed physisorbed at zirconia surfaces, provided that they contain oxygen defects $\mathrm{V}_{\mathrm{O}}^{\bullet \bullet}$ under reducing conditions. Therefore, the assumption for a weak interaction is well justified for the domain of electrolytic stability of YSZ where the oxygen vacancy concentration is not dependent on the oxygen activity in the gas phase.

As a simple approximation orbital energies obtained with a density-functional/Hartree-Fock hybrid method PW1PW were considered. $^{29}$ Although it has been shown ${ }^{30}$ that the absolute values of such one-electron levels deviate from measured ionization potentials, they provide the correct trend within certain classes of compounds. ${ }^{31}$ The second and more reliable method is configuration interaction with single excitations and corrections from double excitations (CIS(D)). ${ }^{32}$ The calculations were performed with the quantum-chemical program package Gaussian $03 .{ }^{33}$ Initially a $6-311++\mathrm{G}(2 \mathrm{~d}, 2 \mathrm{p})$ basis set was used as in a previous $\mathrm{N}_{2}$ XPS study. ${ }^{34}$ Photo-ionization was approximated by excitation of the core electrons into unbound Rydberg states. For this purpose a diffuse $s$ function with orbital exponent 0.0001 was added to the basis. As dinitrogen anions are unstable with respect to the neutral species (relative energies 2.3 and $10.8 \mathrm{eV}$ for $\mathrm{N}_{2}^{-}$and $\mathrm{N}_{2}^{2-}$, respectively), an unbiased self-consistent field procedure lead to Rydberg states where the diffuse s orbital was occupied 
instead of a localized orbital. The localized states had to be stabilized by level shifting techniques.

\subsection{Ex situ SIMS analysis}

After the in situ XPS and electrochemical experiments the samples were analyzed ex situ by time-of-flight secondary ion mass spectrometry (ToF-SIMS IV, ION-TOF, Münster, Germany), in the following abbreviated simply as SIMS, with the following typical parameters: a beam of $25 \mathrm{keV} \mathrm{Ga}^{+}$, rastered over $100 \mu \mathrm{m} \times 100 \mu \mathrm{m}$, was used to generate secondary ions for analysis $\left(I_{\mathrm{Ga}}=1 \mathrm{pA}\right)$. Sputter etching of the surface was carried out with a beam of $2 \mathrm{keV} \mathrm{Cs}^{+}$rastered over $300 \mu \mathrm{m} \times 300 \mu \mathrm{m}\left(I_{\mathrm{Cs}}=150 \mathrm{nA}\right)$. Charge compensation was achieved by flooding the surface with electrons $\left(I_{e}>1 \mu \mathrm{A}\right)$ of energy less than $20 \mathrm{eV}$. We quantified the nitrogen concentrations in the crystals by comparing the intensity ratios $I\left({ }^{90} \mathrm{Zr}^{14} \mathrm{~N}^{-}\right) / I$ $\left({ }^{96} \mathrm{Zr}^{16} \mathrm{O}^{-}\right)$with intensity ratio determined from a $\mathrm{N}$-implanted sample, i.e. YSZ: $\mathrm{N}$ with known nitrogen content.

\section{Results}

\subsection{Electrochemical studies}

A typical steady state potentiostatic current-voltage curve during cathodic and anodic polarization in nitrogen atmosphere is shown in Fig. 2. Down to $E=-1 \mathrm{~V}$ (Fig. 2a) the current is negligibly small and virtually constant. At higher cathodic potentials two regions can be defined-region 1 (from $E=-1 \mathrm{~V}$ to $E=-2 \mathrm{~V}$ ) and region 2 (from $E=-2 \mathrm{~V}$ to $E=-3 \mathrm{~V}$ ), where the current increase is more pronounced in the second region. A diffusion limiting current $I_{d}=0.25 \mathrm{~mA}$ for the region 1 was determined using the inflection point of the current-voltage curve in the potential range $-1.7 \mathrm{~V}$ to $-2.25 \mathrm{~V}$. The curve has been further deconvoluted by a simple substraction into two partial curves (included in Fig. 2a) each representing an individual electrochemical process. At lower overvoltages (from $-1000 \mathrm{mV}$ up to $-1700 \mathrm{mV}$ ) a Tafel slope (extracted from $\eta v s$. $\log i$ plot) of $b_{1}=0.26 \mathrm{~V}$ and at overvoltages more negative than $-2000 \mathrm{mV}$ a slope of $\mathrm{z} b_{2}=0.65 \mathrm{~V}$ were calculated.

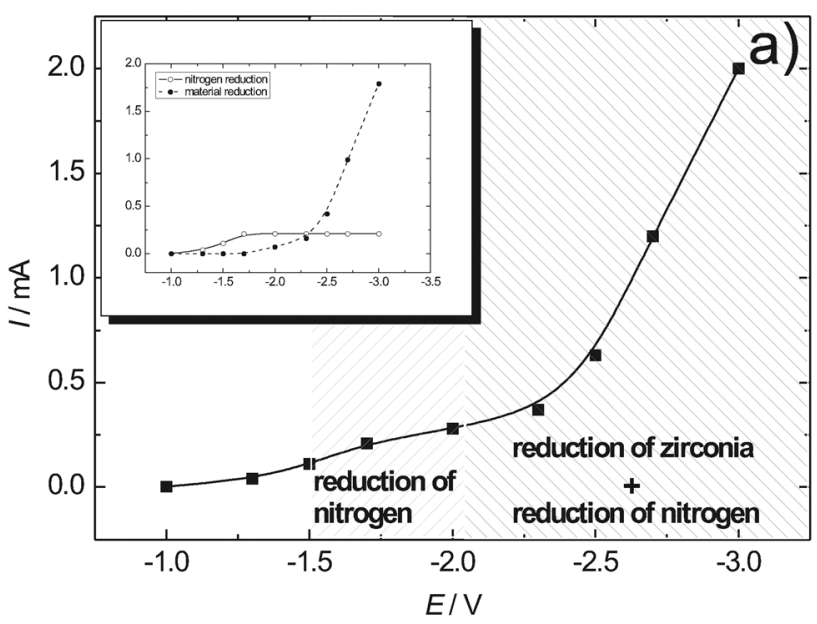

After the samples have been polarized cathodically in nitrogen (for a time of $24 \mathrm{~h}$ at potentials down to $E=-2.5 \mathrm{~V}$ ) we performed anodic experiments in the same atmosphere. The current-voltage characteristics of the anodic process, i.e. the oxidation of nitrogen ions and/or oxide ions is presented in Fig. 2b.

The current increases strongly with the applied voltage up to $E=0.65 \mathrm{~V}$ and then decreases at higher voltages. This passivation-like behaviour of the electrode is reversible and restarting the experiment from $0 \mathrm{~V}$ the curve can be reproduced without change in the electrochemical characteristics.

\subsection{In situ XPS measurements and theoretical calculations}

3.2.1 The $\mathbf{N}$ 1s signal. During the steady state polarization measurements (as represented in Fig. 2) complete XPS spectra have been recorded at each point of the current-voltage curve. No nitrogen signal was detected at voltages down to $-1.5 \mathrm{~V}$. When $-1.5 \mathrm{~V}$ was exceeded a broad peak at binding energies between $397 \mathrm{eV}$ and $398 \mathrm{eV}$ appeared.

The intensity of the signal increases with time $\left(t_{1}-t_{4}\right)$, and the peak (at $\left.t_{4}\right)$ is broad and indicates more than one component (Fig. 3). In order to achieve the highest time resolution only single scans (one scan takes a time of approximately $60 \mathrm{~s}$ with time intervals between the scans of approx. $75 \mathrm{~s}$ ) were performed. Due to the poor statistics and high noise/signal ratio no fit was performed, but the splitting of the nitrogen signal was confirmed by later experiments at even more negative voltages and better statistics where this effect was more pronounced. The appearance of the $\mathrm{N}$ 1s peak is reversible and after switching the voltage off the peak disappears completely within approx. $5 \mathrm{~min}\left(t_{5}-t_{8}\right)$.

Applying a more negative potential to the micro-electrode the intensity of the nitrogen peak increases and the peak becomes broader. These changes were reversible for short polarization times (up to few minutes) until a voltage of $-2.5 \mathrm{~V}$ was achieved. At lower (more negative) voltages the nitrogen peak remains constant in position and intensity after switching the voltage off.

Fig. 4 presents the $\mathrm{N}$ 1s signal during electrochemical polarization with voltages down to $E=-3 \mathrm{~V}$. The peak

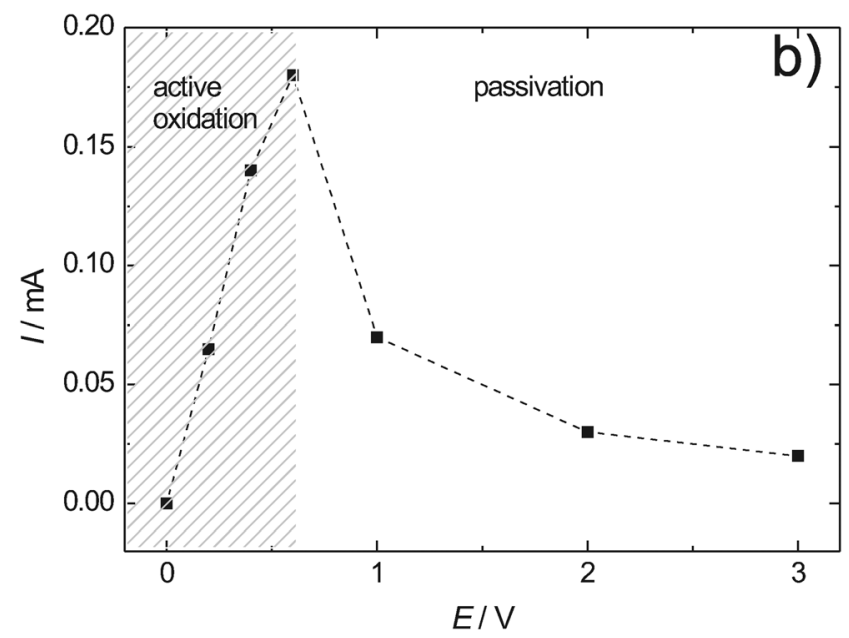

Fig. 2 Cathodic (a) and anodic (b) current-voltage polarisation curves with an iridium micro-electrode, $p\left(\mathrm{~N}_{2}\right)=10^{-5} \mathrm{~Pa}, T=723 \mathrm{~K}$. 


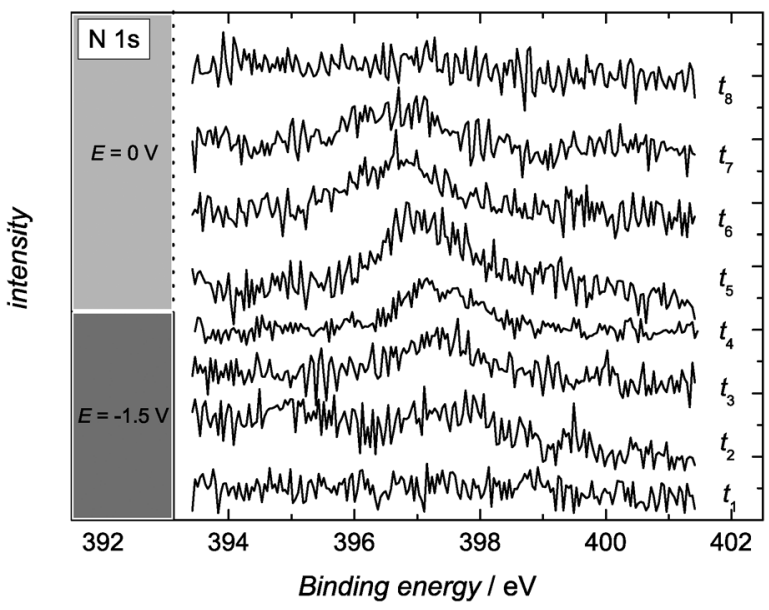

Fig. 3 Consecutive $\mathrm{N}$ 1s spectra at YSZ/iridium micro-electrode/ $\mathrm{N}_{2}$ boundary after applying a voltage of $E=-1.5 \mathrm{~V}$ and switching the voltage off. $t$ - the time (increasing from $t_{1}$ to $t_{8}$ ); $T=723 \mathrm{~K}$, $p\left(\mathrm{~N}_{2}\right)=10^{-5} \mathrm{~Pa}$.

deconvolution revealed three components at binding energies of $B E_{1}=397.2 \mathrm{eV}, B E_{2}=397.7 \mathrm{eV}$ and $B E_{3}=398.6 \mathrm{eV}$, respectively. The fit parameters obtained by the deconvolution procedure are given in Table 1.

The relative areas of the three components of the $\mathrm{N}$ 1s peak were calculated from the fit data and are shown in Table 2. The component at $B E_{1}$ decreases with decreasing voltage from 0.65 (at $E=-1.7 \mathrm{~V}$ ) down to 0.25 at $E=-3 \mathrm{~V}$. The relative component area for $B E_{2}$ remains almost constant for voltages up to $-2.5 \mathrm{~V}$ and then increases with a maximum value of

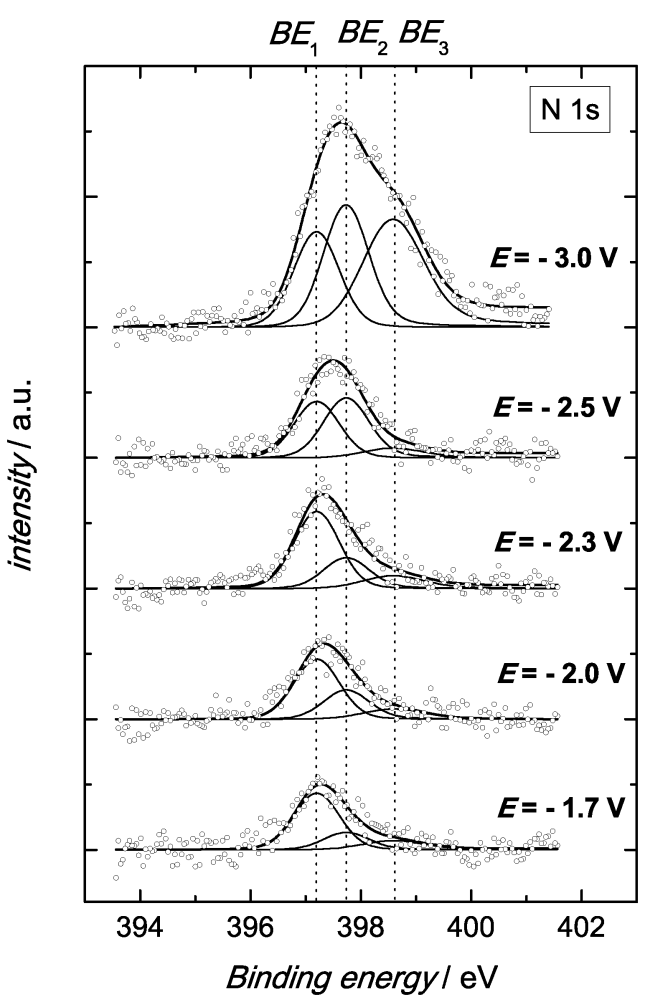

Fig. $4 \mathrm{~N}$ 1s spectra at $\mathrm{YSZ} /$ iridium micro-electrode/ $\mathrm{N}_{2}$ boundary at different polarisation potentials, $p\left(\mathrm{~N}_{2}\right)=10^{-5} \mathrm{~Pa}, T=723 \mathrm{~K}$.
0.46 at $E=-2.5 \mathrm{~V}$. The relative area of $B E_{3}$ is comparatively low-in average 0.14 but sharply increases for $E=-3 \mathrm{~V}$. The total area of the nitrogen peak (i.e. the sum of the three components) increases with the decreasing voltage.

In addition we recorded the $\mathrm{N}$ 1s spectra (shown in Fig. 5) as a function of the distance to the electrode, i.e. the nitrogen distribution in the vicinity of the iridium tip. Close to the micro-electrode the $\mathrm{N}$ 1s signal is broad and of high intensity and it contains all three components shown in the fit in Fig. 4. Increasing the distance from the electrode the intensity of the peak decreases and the components at $B E_{1}$ and $B E_{2}$ become dominant. The $\mathrm{N}$ 1s signal decreases completely to zero at a distance of approximately $1.5 \mathrm{~mm}$ from the tip.

3.2.2 Theoretical calculation of $\mathbf{N} 1 \mathrm{~s}$ peak position. The calculated values for the $\mathrm{N} 1 \mathrm{~s}$ binding energy are shown in Table 3. In the first two columns it is assumed that the electrons provided by the electrochemical polarization remain localized at the molecule. The values in the third and the fourth column account for delocalization and distribution of the electron density around the molecule, e.g. at the YSZ electrode surface.

3.2.3 The $\mathrm{O}$ 1s signal. The O 1s signals at different applied voltages are shown in Fig. 6.

Three components can be distinguished with binding energies of $B E_{1}=531.0 \mathrm{eV}, B E_{2}=531.4 \mathrm{eV}$ and $B E_{3}=$ $532.6 \mathrm{eV}$ respectively. The fit parameters are given in Table 4.

Before the polarization experiments (i.e. $E=0 \mathrm{~V}$ ) the main contribution to the $\mathrm{O} 1 \mathrm{~s}$ signal intensity is $B E_{2}$ at a binding energy of $531.4 \mathrm{eV}$. Upon polarization the intensities of all signals changed (see Table 5) where the contribution of the component $B E_{1}$ is dominant at potentials $E \geq-2.5 \mathrm{~V}$.

The total peak area increases for $E=-1.0 \mathrm{~V}$ and then decreases for $E=-2.0 \mathrm{~V}$ and $E=-2.5 \mathrm{~V}$ and increases again at $E=-3.0$. The oxygen peak recorded as a function of the distance to the micro-electrode is presented in Fig. 7.

Close to the iridium tip the main component of the $\mathrm{O} 1 \mathrm{~s}$ peak is at $B E_{1}$. With increasing distance the contribution of $B E_{1}$ becomes smaller and the main contribution to the total peak intensity is the signal at $B E_{2}$. The total peak area decreases slightly from the point at the micro electrode to the distance of $900 \mu \mathrm{m}$ and again slowly increases to remain constant at distances larger than $1.3 \mathrm{~mm}$.

3.2.4 The Zr 3d signal. The $\mathrm{Zr} 3 \mathrm{~d}$ signal appears as a doublet as a result of spin orbit splitting. The two components $3 d 5 / 2$ and $3 d 3 / 2$ in Fig. 8 for the unpolarized material and material under an applied voltage of $E=-1.7 \mathrm{~V}$ are found at binding energies of $183.3 \mathrm{eV}$ and $185.7 \mathrm{eV}$, respectively, which is in agreement with our previous studies. ${ }^{19}$ The signal remains unchanged in position and intensity upon polarization down to $E=-2.0 \mathrm{~V}$. At and below $E=-2.0 \mathrm{~V}$ four doublets can be separated, each of them representing $\mathrm{Zr}$ ions in a different chemical environment. The XPS spectra of $\mathrm{Zr} 3 \mathrm{~d}$ doublet at three potentials up to $-3.0 \mathrm{~V}$ are presented in Fig. 9. The $\mathrm{Zr} 3 \mathrm{~d}$ $5 / 2$ peaks were ordered according to their binding energies as follows: $B E_{1}=179.4 \mathrm{eV} ; B E_{2}=180.5 \mathrm{eV} ; B E_{3}=181.4 \mathrm{eV}$ and $B E_{4}=183.3 \mathrm{eV}$. The lower is the binding energy the lower (less positive) is the formal oxidation state of the zirconium 
Table 1 Fit parameters for N 1 s peak $^{a}$

\begin{tabular}{lllll}
\hline Binding energy/eV & $\mathrm{GW} / \mathrm{eV}$ & $\mathrm{LW} / \mathrm{eV}$ & $\mathrm{FWHM} / \mathrm{eV}$ & Sym. factor \\
\hline$B E_{1}=397.2$ & 0.91 & 0.1 & 0.96 & 0.006 \\
$B E_{2}=397.7$ & 0.90 & 0.1 & 0.97 & 0.02 \\
$B E_{3}=398.6$ & 1.21 & 0.1 & 1.32 & 0.06
\end{tabular}

$B E_{3}=398.6$

${ }^{a} \mathrm{GW}$ is the Gaussian width; LW is the Lorenzian width and FWHM is the full width half maximum of the peaks.

Table 2 Relative component areas for N 1s peaks

\begin{tabular}{llll}
\hline Voltage $/ \mathrm{V}$ & $A_{B E_{1}}$ & $A_{B E_{2}}$ & $A_{B E_{3}}$ \\
\hline-1.7 & 0.65 & 0.20 & 0.15 \\
-2.0 & 0.57 & 0.29 & 0.14 \\
-2.3 & 0.61 & 0.25 & 0.14 \\
-2.5 & 0.43 & 0.46 & 0.11 \\
-3.0 & 0.25 & 0.33 & 0.42 \\
\hline
\end{tabular}

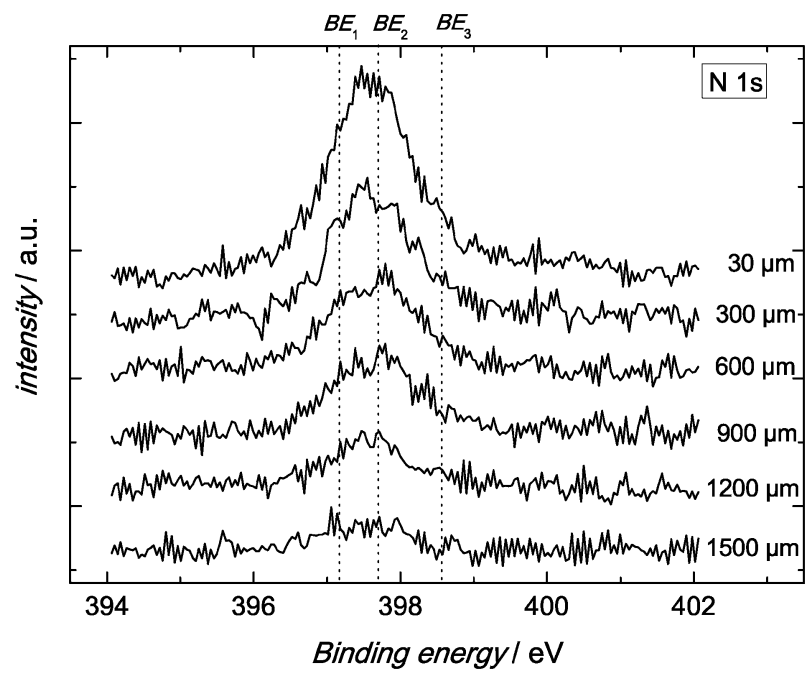

Fig. $5 \mathrm{~N}$ 1s spectra as a function of the distance to the iridium microelectrode after applying a voltage of $E=-2.5 \mathrm{~V}, p\left(\mathrm{~N}_{2}\right)=10^{-5} \mathrm{~Pa}$, $T=723 \mathrm{~K}$.

Table 3 Calculated values for the N 1s binding energy for nitrogen molecule and molecular ions and the expected shift due to the additional negative charge

\begin{tabular}{llllll}
\hline & \multicolumn{2}{l}{ Localized states } & & \multicolumn{2}{l}{ Rydberg states } \\
\cline { 2 - 3 } Nitrogen species & PW1PW & CIS(D) & & PW1PW & CIS(D) \\
\hline $\mathrm{N}_{2}$ & 394.54 & 402.59 & & 394.54 & 402.59 \\
$\mathrm{~N}_{2}^{-}$ & 385.03 & 389.18 & & 392.13 & 401.54 \\
$\mathrm{~N}_{2}^{2-}$ & 378.98 & 375.76 & & 390.94 & 400.18 \\
\hline
\end{tabular}

ion. The fitting parameters for all peaks are given in Table 6 . The displacement $\Delta$ between the $3 \mathrm{~d} 5 / 2$ and $3 \mathrm{~d} 3 / 2$ components is $2.4 \mathrm{eV}$ and was constant for all experimental conditions. The peak intensity ratio $I_{5 / 2} / I_{3 / 2}$ was 1.5 for all peaks.

The calculated relative areas of the peaks are presented in Table 7. Up to $E=-2.0 \mathrm{~V}$ the only component present was $B E_{4}$ at binding energy $183.3 \mathrm{eV}$ corresponding to the highest oxidation state $\mathrm{Zr}^{4+}$ of the zirconium ion. The relative component areas of the reduced species (the other three

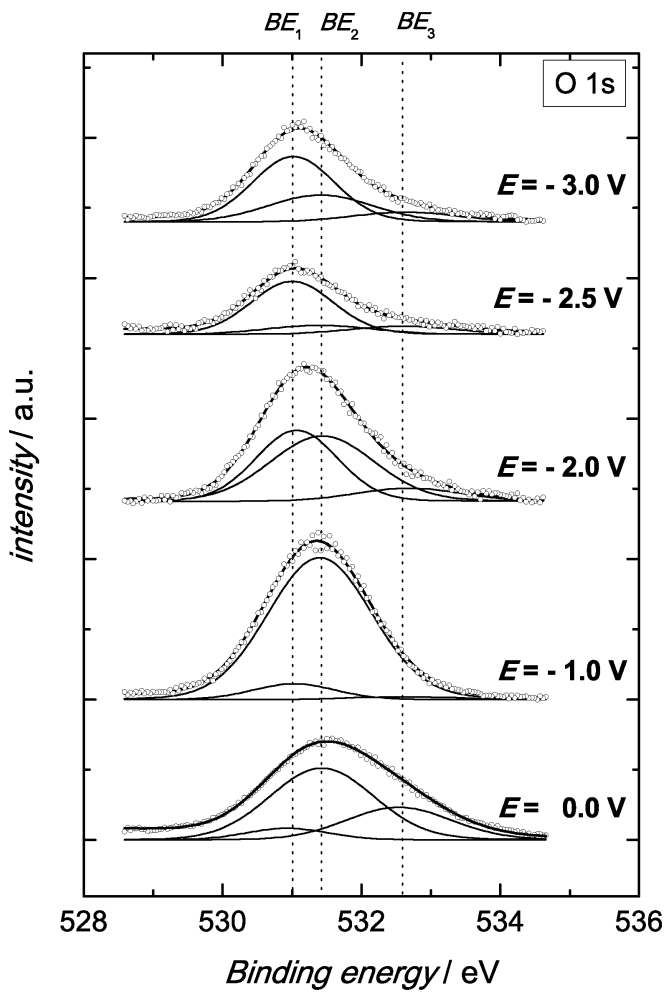

Fig. $6 \mathrm{O} 1 \mathrm{~s}$ spectra at $\mathrm{YSZ} /$ iridium micro-electrode $/ \mathrm{N}_{2}$ boundary at different voltages, $p\left(\mathrm{~N}_{2}\right)=10^{-5} \mathrm{~Pa}, T=723 \mathrm{~K}$.

Table 4 Fit parameters for O 1s peak

\begin{tabular}{lllll}
\hline Binding energy/eV & $\mathrm{GW} / \mathrm{eV}$ & $\mathrm{LW} / \mathrm{eV}$ & $\mathrm{FWHM} / \mathrm{eV}$ & Sym. factor \\
\hline$B E_{1}=531.0$ & 1.33 & 0.1 & 1.39 & 0.02 \\
$B E_{2}=531.4$ & 1.71 & 0.1 & 1.77 & 0.06 \\
$B E_{3}=532.6$ & 1.73 & 0.1 & 1.79 & 0.06 \\
\hline
\end{tabular}

Table 5 Relative component areas for O 1s peaks

\begin{tabular}{llll}
\hline Voltage/V & $A_{B E_{1}}$ & $A_{B E_{2}}$ & $A_{B E_{3}}$ \\
\hline 0 & 0.13 & 0.60 & 0.27 \\
-1.0 & 0.08 & 0.90 & 0.02 \\
-2.0 & 0.42 & 0.48 & 0.10 \\
-2.5 & 0.71 & 0.16 & 0.13 \\
-3.0 & 0.59 & 0.30 & 0.10 \\
\hline
\end{tabular}

signals) increase by increasing the applied potential and the relative area of the oxide component $\left(\mathrm{Zr}^{4+}\right.$ ion) decreases.

As shown in Fig. 10, moving away from the electrodeelectrolyte interface the $\mathrm{Zr} 3 \mathrm{~d}$ peak changes its shape. Close to the tip the components at $B E_{1}, B E_{2}$ and $B E_{3}$ dominated. At distances larger than approximately $1100 \mu \mathrm{m}$ the main component becomes $B E_{4}$. The total area of the $\mathrm{Zr} 3 \mathrm{~d}$ peak decreases almost linearly by $18 \%$ within the total distance of $1500 \mu \mathrm{m}$.

3.2.5 The Y 3d signal. The $Y 3 d$ peak also appears as a doublet with two components Y $3 d 5 / 2$ and Y $3 d$ 3/2. Without applied voltage only one doublet is registered at a binding energy $B E_{1}=158.3 \mathrm{eV}$. Upon polarization a second peak Y $3 \mathrm{~d}$ 


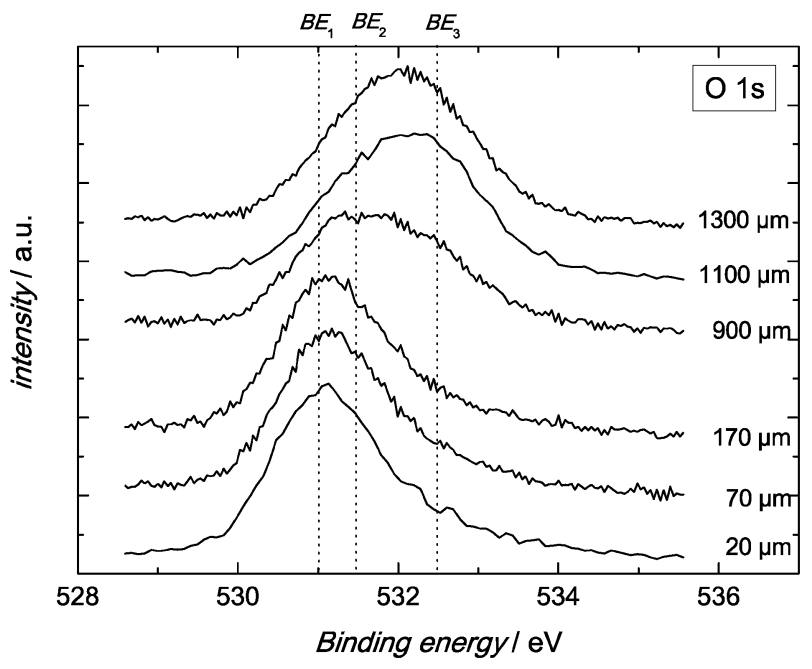

Fig. $7 \mathrm{O} 1 \mathrm{~s}$ spectra as a function of the distance to the iridium micro-electrode after applying a voltage of $E=-2.5 \mathrm{~V}, p\left(\mathrm{~N}_{2}\right)=10^{-5}$ $\mathrm{Pa}, T=723 \mathrm{~K}$.

Table 6 Fit parameters for $\mathrm{Zr} 3 \mathrm{~d}_{5 / 2}$ peak

\begin{tabular}{lllll}
\hline Binding energy/eV & $\mathrm{GW} / \mathrm{eV}$ & $\mathrm{LW} / \mathrm{eV}$ & $\mathrm{FWHM} / \mathrm{eV}$ & Sym. factor \\
\hline$B E_{1}=179.43$ & 0.83 & 0.1 & 0.93 & 0.08 \\
$B E_{2}=180.45$ & 1.94 & 0.1 & 2.04 & 0.03 \\
$B E_{3}=181.40$ & 1.07 & 0.1 & 1.14 & 0.02 \\
$B E_{4}=183.33$ & 1.51 & 0.1 & 1.63 & 0.06 \\
\hline
\end{tabular}

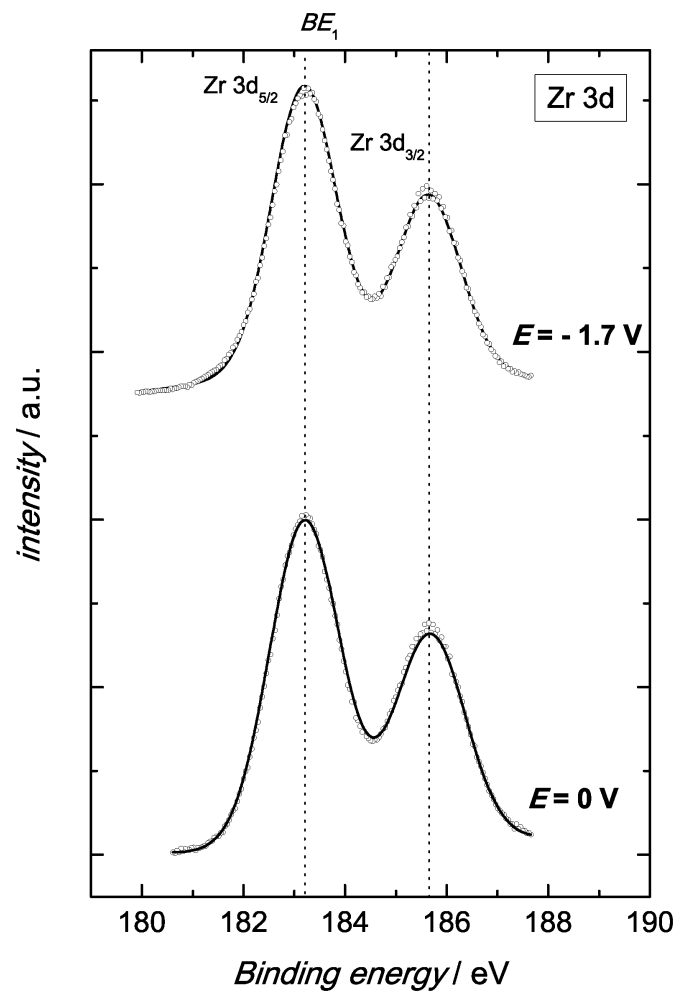

Fig. $8 \mathrm{Zr} 3 \mathrm{~d}$ spectra at $\mathrm{YSZ} /$ iridium micro-electrode/ $\mathrm{N}_{2}$ boundary at different voltages, $p\left(\mathrm{~N}_{2}\right)=10^{-5} \mathrm{~Pa}, T=723 \mathrm{~K}$.

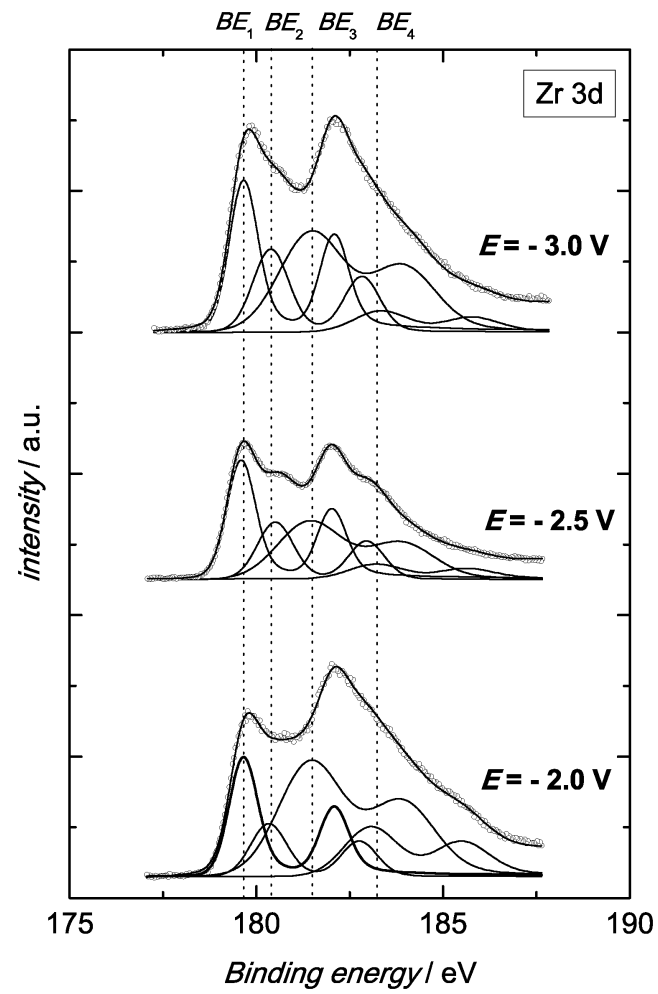

Fig. $9 \mathrm{Zr} 3 \mathrm{~d}$ spectra at $\mathrm{YSZ} /$ iridium micro-electrode/ $\mathrm{N}_{2}$ boundary at different voltages, $p\left(\mathrm{~N}_{2}\right)=10^{-5} \mathrm{~Pa}, T=723 \mathrm{~K}$.

Table 7 Relative component areas for $\mathrm{Zr} 3 \mathrm{~d}$ peaks

\begin{tabular}{cllll}
\hline Voltage/V & $A_{B E_{1}}$ & $A_{B E_{2}}$ & $A_{B E_{3}}$ & $A_{B E_{4}}$ \\
\hline 0.0 & - & - & - & 1 \\
-1.7 & - & - & - & 1 \\
-2.0 & 0.23 & 0.46 & 0.13 & 0.18 \\
-2.5 & 0.34 & 0.33 & 0.20 & 0.13 \\
-3.0 & 0.30 & 0.40 & 0.20 & 0.10 \\
\hline
\end{tabular}

appears at a binding energy $B E_{2}=156.8 \mathrm{eV}$. The XPS spectra during the polarization at different applied voltages are presented in Fig. 11.

The component at the lower binding energy is of low intensity at voltages of $-2 \mathrm{~V}$ and $-2.5 \mathrm{~V}$ and is present with significant intensity only at applied voltage of $-3 \mathrm{~V}$. The fit parameters for both peaks are given in Table 8 .

The distance between the $3 \mathrm{~d} 5 / 2$ and $3 \mathrm{~d} 3 / 2$ components was $\Delta=2.1 \mathrm{eV}$ and the ratio $I_{5 / 2} / I_{3 / 2}$ was 1.5 for the both peaks. The relative peak areas are given in Table 9.

The relative component area of the peak at $B E_{1}$ decreases by $64 \%$ with the decreasing voltage and $A_{B E_{2}}$ increases. The total peak area changes with the applied voltage with a maximum area calculated at $E=-3 \mathrm{~V}$.

In Fig. 12 the Y $3 d$ signal is presented as a function of the distance to the micro-electrode.

Moving away from the electrode the shape of the spectrum changes. The reduced component dominates close to the electrode and the oxidized component away from the electrode. The reduced component disappears fully at a distance more than $1500 \mu \mathrm{m}$ from the iridium tip. 


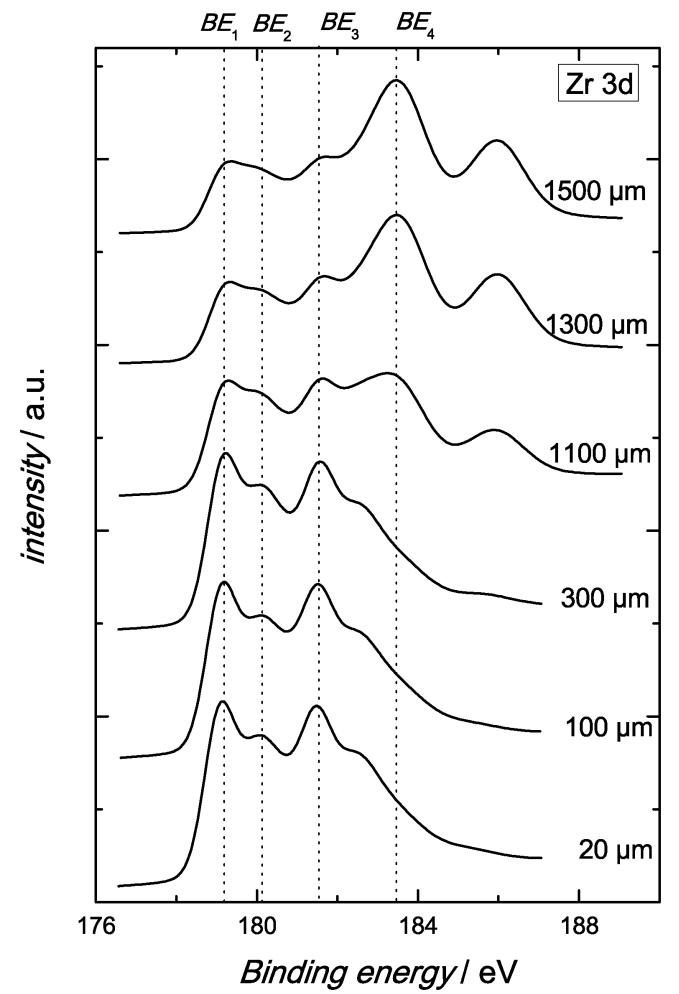

Fig. $10 \mathrm{Zr} 3 \mathrm{~d}$ spectra as a function of the distance to the iridium micro-electrode after applying a voltage of $E=-2.5 \mathrm{~V}, p\left(\mathrm{~N}_{2}\right)=$ $10^{-5} \mathrm{~Pa}, T=723 \mathrm{~K}$.

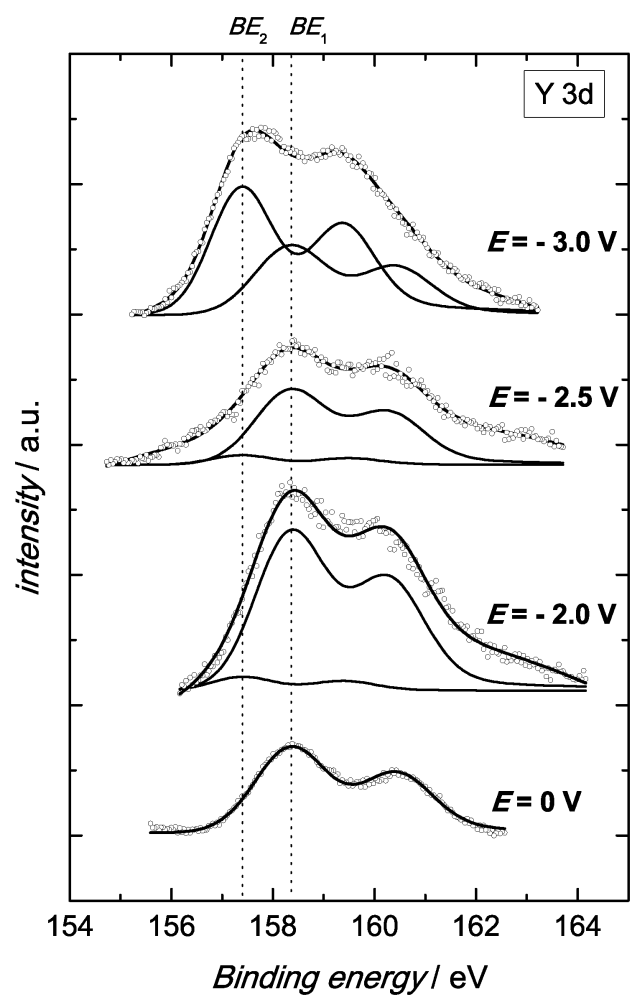

Fig. $11 Y$ Y $d$ spectra at $Y S Z /$ iridium micro-electrode/ $\mathrm{N}_{2}$ boundary at different voltages, $p\left(\mathrm{~N}_{2}\right)=10^{-5} \mathrm{~Pa}, T=723 \mathrm{~K}$.
Table 8 Fit parameters for $\mathrm{Y} 3 \mathrm{~d}_{5 / 2}$ peak

\begin{tabular}{lllll}
\hline Binding energy/eV & $\mathrm{GW} / \mathrm{eV}$ & $\mathrm{LW} / \mathrm{eV}$ & $\mathrm{FWHM} / \mathrm{eV}$ & Sym. factor \\
\hline$B E_{1}=158.33$ & 1.58 & 0.1 & 1.68 & 0.04 \\
$B E_{2}=156.76$ & 1.58 & 0.1 & 1.68 & 0.04 \\
\hline
\end{tabular}

Table 9 Relative component areas for Y 3d peaks

\begin{tabular}{lll}
\hline Voltage/V & $A_{B E_{1}}$ & $A_{B E_{2}}$ \\
\hline 0.0 & 1.00 & - \\
-2.0 & 0.94 & 0.06 \\
-2.5 & 0.89 & 0.11 \\
-3.0 & 0.36 & 0.64 \\
\hline
\end{tabular}

Table 10 Component ratio

\begin{tabular}{llll}
\hline Voltage/V & $\mathrm{Y} / \mathrm{Zr}$ & $\mathrm{N} / \mathrm{O}$ & Nonmetal/Metal \\
\hline 0.0 & 0.16 & - & 2.3 \\
-2.0 & 0.14 & 0.08 & 2.0 \\
-2.5 & 0.12 & 0.22 & 1.5 \\
-3.0 & 0.16 & 0.43 & 1.7 \\
\hline
\end{tabular}

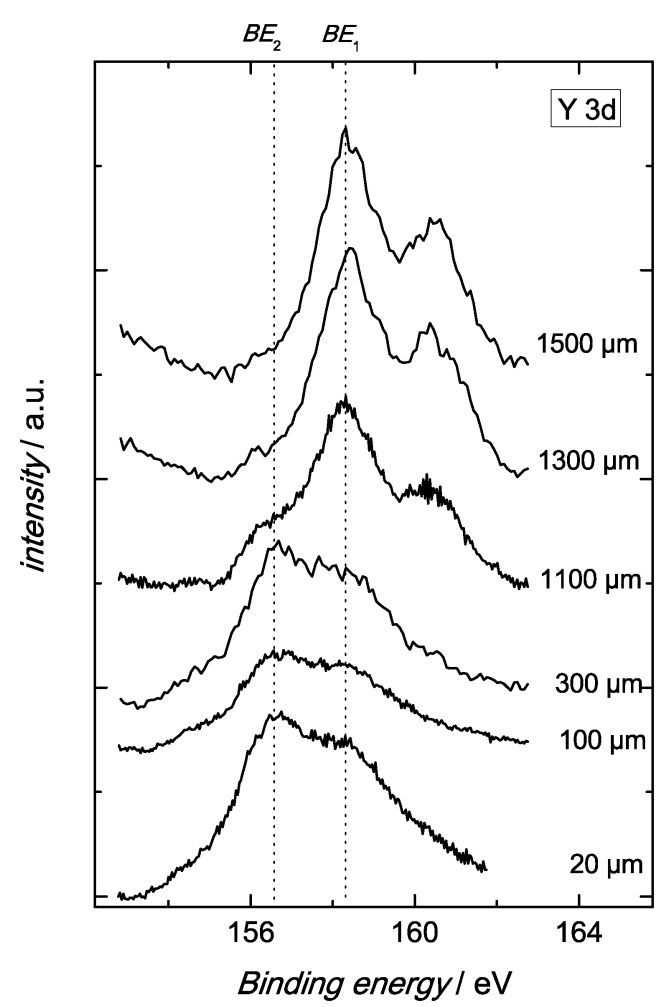

Fig. 12 Y $3 d$ spectra as a function of the distance to the iridium micro-electrode after applying a voltage of $E=-2.5 \mathrm{~V}, p\left(\mathrm{~N}_{2}\right)=10^{-5} \mathrm{~Pa}$, $T=723 \mathrm{~K}$.

3.2.6 Nonmetal/Metal, $\mathrm{Y} / \mathrm{Zr}$ and $\mathrm{N} / \mathrm{O}$ ratio. The nonmetal/metal ratio was calculated according to a standard procedure using the component peak area and the sensitivity factor (see Table 10). At the three phase boundary we found for the initial conditions $(E=0 \mathrm{~V})$ 2.3. Applying a negative voltage this ratio remains 2.0 down to $E=-2 \mathrm{~V}$ then 
decreases to 1.5 at $E=-2.5 \mathrm{~V}$ and increases again to 1.7 at a potential value of $-3 \mathrm{~V}$. The $\mathrm{Y} / \mathrm{Zr}$ ratio decreases slightly by decreasing the voltage from 0.16 to 0.12 and increases to 0.16 at $-3 \mathrm{~V}$. The $\mathrm{N} / \mathrm{O}$ ratio starts from 0 to reach 0.43 at $E=-3 \mathrm{~V}$ corresponding to 18 at. $\%$ nitrogen.

\subsection{Ex situ SIMS analysis}

The ex situ SIMS analysis was performed after the nitrogen incorporation experiments; the results are shown in Fig. 13.

Nitrogen was found (laterally in the XY image) at the contact interface and around the micro-electrode. The images of YZ and XZ "cross sections" show the depth distribution of $\mathrm{N}$, mainly incorporated beneath the electrode.

\section{Discussion}

In the following discussion we will concentrate on three important issues: (i) the incorporation of nitrogen ions into YSZ as a result of an electric potential driven process and not of a chemical reaction; (ii) the mechanism of the reduction and the character of the nitrogen species involved; and (iii) the concurrent process of reduction of the YSZ single crystal which is supposed to occur at voltages lower than $E<-2 \mathrm{~V}$.

\subsection{Electrochemical reduction of dinitrogen}

4.1.1 XPS studies during cathodic polarisation-the $N$ 1s peak. In previous steady state polarization experiments in $10^{5} \mathrm{~Pa}$ nitrogen atmosphere we showed that the electrochemical reduction of molecular nitrogen on YSZ electrolyte is a multistep charge transfer process involving more intermediate states. $^{21} \mathrm{We}$ proposed that at gold microelectrodes and a temperature of $973 \mathrm{~K}$ the reduction mechanism proceeds via three stages with a rate determining step $\mathrm{N}_{2}^{-}+\mathrm{e}^{-}=\mathrm{N}_{2}^{2-}$ and that in fact the charge transfer and not the ion diffusion controls the overall process of nitrogen incorporation. In our actual cell arrangement due to the specifics of the experimental setup we used iridium as material for the working electrode because of its mechanical stability and hardness, ensuring a constant contact force of the microelectrode on YSZ in the whole temperature range. Iridium has a different work function than gold and possibly a different catalytic activity towards nitrogen, and the reduction mechanism may be completely different taking into account that the working temperature is much lower i.e. $723 \mathrm{~K}$ instead of $973 \mathrm{~K}$. However, for some general reasons i.e. high

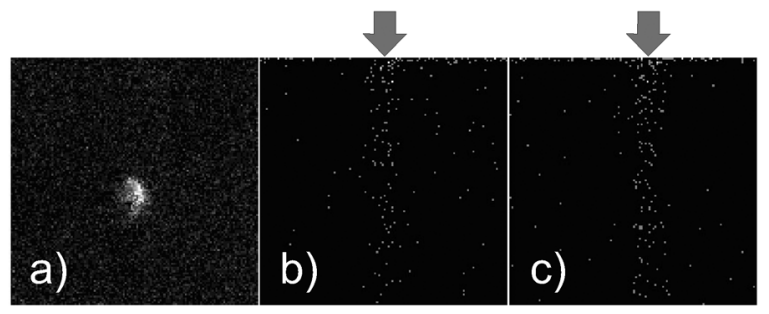

Fig. 13 SIMS image of nitrogen distribution around the electrode after cathodic polarization. (a) XY surface image (field of view $251 \times 251 \mu \mathrm{m}^{2}$ ); (b) $\mathrm{XZ}$ and (c) $\mathrm{YZ}$ images perpendicular to the surface (field of view $251 \times 0.4 \mu^{2}$ ). The arrows mark the initial position of the microelectrode. dissociation enthalpy of $\mathrm{N}_{2}$ molecule and the total number of electrons (six) required for the complete reduction, we do not expect a simple Nernstian single step process.

The cathodic current-voltage curve shown in Fig. 2a is composed from the contributions of two processes. We assign the first process (in potential region 1) to electrochemical reduction of nitrogen and the second process to the reduction of the electrolyte, more precisely to the reduction of the metal ions. By combination of steady state electrochemical measurements with in situ XPS monitoring we were able to determine the chemical shift of ions in the YSZ electrolyte and also the appearance of new species, i.e. nitrogen during electrochemical polarisation and to distinguish individual electrochemical processes and to assign to them a specific electrode reaction.

The initial pressure in the experimental chamber was $10^{-8}$ $\mathrm{Pa}$ and introducing nitrogen up to the pressure of $10^{-5} \mathrm{~Pa}$ (typical for our working conditions) we did not observe a $\mathrm{N} 1 \mathrm{~s}$ peak without applied voltage, neither with fully oxidized material nor with electrochemically pre-reduced YSZ. So we conclude that neither adsorption nor chemical processes at the electrolyte surface, at the microelectrode or at the Ir/YSZ three phase boundary can be a reason for appearing of nitrogen signal.

Under cathodic polarization we first detect nitrogen signal at $E=-1.5 \mathrm{~V}$ (Fig. 3). The response of the XPS N 1s peak to the applied potential is reversible and time dependent. After time $t_{4}$ is exceeded the peak intensity remains constant. The reversibility of the process is demonstrated by switching the voltage off where the signal disappears completely within approximately the same time. The broad $\mathrm{N}$ 1s peak indicates more than one nitrogen component, which is confirmed by improving the statistics at higher potentials. We assume that the nitrogen species reduced at the electrode accumulate only in the first top monolayers but are not permanently incorporated in the YSZ single crystal for the time of our experiment. They easily desorb from the surface when the voltage is switched off. Despite the XPS results indicating that the reduction process begins at $E=-1.5 \mathrm{~V}$ we strongly believe the process starts earlier, at a voltage of approximately $-1.25 \mathrm{~V}$. The reason for this conclusion is that XPS requires a local surface coverage of at least $0.2 \%$ in order to be able to detect a signal and obviously this coverage is achieved at $E-1.5 \mathrm{~V}$ but not at more positive potentials. However, based on nitrogen incorporation experiments at constant voltages (for a time of $30 \mathrm{~min}$ and $60 \mathrm{~min}$ ) combined with ex situ SIMS analysis we found practically that the reduction/incorporation process starts even earlier at $E=-1.25 \mathrm{~V}$.

The identification of the three nitrogen species we detected (Table 1) under polarisation is difficult due to a broad range of possible assignments. The reference value for the $\mathrm{N} 1 \mathrm{~s}$ binding energy of the $\mathrm{N}^{3-}$ state is suggested as $398.5 \mathrm{eV}$ in ref. 35 for the standard compound boron nitride. As $\mathrm{BN}$ is a covalent rather than an ionic compound this value can only serve as a rough orientation. In XPS studies on nitrogen containing zirconia different binding energies for the $\mathrm{N}$ 1s peak have been reported, depending mainly on the stoichiometry of the compound. A summary of the suggested binding energies is given in Table 11. 
Table $11 \mathrm{~N}$ 1s binding energies of different nitrogen containing zirconium compounds

\begin{tabular}{|c|c|c|}
\hline $\mathrm{N} 1 \mathrm{~s}(B E / \mathrm{eV})$ & Compound & Bond \\
\hline 395.8 & $\mathrm{ZrN}_{2}$ & Ionic $^{36}$ \\
\hline $396.3,400.05$ & oxinitrides & Ionic $^{37,38}$ \\
\hline $396.4,396.6$ & $\mathrm{Zr}_{3} \mathrm{~N}_{4}$ & Ionic $^{39}$ \\
\hline 396.4 & $\mathrm{ZrO}_{2}: \mathrm{N}$ & Ionic $^{19}$ \\
\hline 397.2 & YSZ:N & $\mathrm{N}^{3-}$ ionic/surface ${ }^{\text {thispaper }}$ \\
\hline 397.3 & $\mathrm{ZrN}$ & Ionic $^{37,38}$ \\
\hline 397.3 & 9.5/13 YSZ: $\mathrm{N}$ & Ionic $^{19}$ \\
\hline 397.6 & $\mathrm{ZrN}$ & Ionic $^{40}$ \\
\hline 397.7 & YSZ:N & $\mathrm{N}_{2}^{-}$ionic/surface ${ }^{\text {thispaper }}$ \\
\hline 398.5 & $\mathrm{BN}$ & Covalent $^{35}$ \\
\hline 398.6 & YSZ:N & $\mathrm{N}_{2}^{2-}$ ionic/surface ethispaper $^{\text {the }}$ \\
\hline 400.9 & $\mathrm{~N}_{2}$ & Covalent $^{41}$ \\
\hline 402.6 & $7 Y S Z: N$ & (Dinitrogen) $\mathrm{M}-\mathrm{N} \equiv \mathrm{N}-\mathrm{M}^{19}$ \\
\hline 402.8 & $\mathrm{ZrON} / \mathrm{TiON}$ & (Dinitrogen) $\mathrm{M}-\mathrm{N} \equiv \mathrm{N}-\mathrm{M}^{42,43}$ \\
\hline 403.2 & $\mathrm{~N}_{2}$ (less justified) & Covalent ${ }^{37,38}$ \\
\hline
\end{tabular}

In general, the increase of the valence state of $\mathrm{N}^{3-}$ towards less negative values (oxidation) is always related to an increasing binding energy. Considering the position of the $\mathrm{N}$ 1s peak of our samples we exclude the existence of molecular nitrogen, because according to the literature the $\mathrm{N}$ 1s signal of $\mathrm{N}_{2}$ appears at a binding energy $E_{\mathrm{b}}=400.9 \mathrm{eV},{ }^{41}$ whereas the main N 1s signals we detected are found between $397 \mathrm{eV}$ and $398 \mathrm{eV}$. The intensity of the nitrogen peak increases with the applied cathodic voltage and the signal becomes broader (see Fig. 4) revealing three components of the total XPS spectra. We assign the first peak at $B E_{1}=397.2 \mathrm{eV}$ to the $\mathrm{N}^{3-}$ ion and the other two components at binding energies $B E_{2}=397.7 \mathrm{eV}$ and $B E_{3}$ at $398.6 \mathrm{eV}$ to (di)nitrogen ions in more positive oxidation states.

We conclude the nitrogen signal we recorded is due to negatively charged ionic species appearing as a result of electrode polarization and in this way we confirm the electrochemical reduction process by in situ XPS. Clearly, the higher cathodic potentials related to higher current densities lead to accumulation of nitrogen species and thus intermediates can be detected by XPS.

A decrease in the intensity, respectively of the concentration of different $\mathrm{N} 1 \mathrm{~s}$ components was also seen as a function of the distance from the electrode/electrolyte interface. Moving away from the electrode we move away from the three phase boundary where the electrochemical reaction takes place. The reduced species diffuse along the electrolyte and correspondingly the concentration of nitrogen ions must be lower. We register a decrease of the intensity of all $\mathrm{N} 1 \mathrm{~s}$ components with increasing distance from the electrode, where the main remaining $\mathrm{N}$ 1s peak is at $397.2 \mathrm{eV}$.

The theoretical calculations of $\mathrm{N} 1 \mathrm{~s}$ binding energy we performed confirmed that in fact the shift of the oxidation state of nitrogen towards less negative values results in an increase of the binding energies. However if we simply assume a localized states, both PW1PW and CIS(D) methods predict large shifts of more than $10 \mathrm{eV}$ for the $\mathrm{N}$ 1s peak upon reduction in the series $\mathrm{N}_{2} \rightarrow \mathrm{N}_{2}^{-} \rightarrow \mathrm{N}_{2}^{2-}$. Although the trend is the same as in our measurements, the absolute values of the calculated shifts are 5-10 times too large.

Alternatively, the Rydberg-type states account for the possibility that the excess electrons (in the valence band) are delocalized at the YSZ surface. The corresponding binding energy shifts are in good agreement to the experimental results. The $\mathrm{N}_{2}-\mathrm{N}_{2}^{-}$shift is $2.4 \mathrm{eV}$ with PW1PW (1.0 eV with CIS(D)) compared to the experimentally determined value $2.3 \mathrm{eV}$. The theoretically predicted $\mathrm{N}_{2}^{-}-\mathrm{N}_{2}^{2-}$ shift is $1.2 \mathrm{eV}(1.4 \mathrm{eV}$ with CIS(D)) and the measured shift is $0.9 \mathrm{eV}$.

Thus, the theoretically calculated binding energies of the Rydberg-type states support our experimental results, suggesting a reduction mechanism involving these three species. Although they are theoretically less justified the PW1PW results fit better to our experimental data than those obtained by CIS(D). The novel unexpected result of our model is the suggested delocalized electronic structure of the adsorbed reduced nitrogen species.

If one assumes the same reduction mechanism as described in ref. 21 with a rate limiting step, $\mathrm{N}_{2}^{-}+\mathrm{e}^{-} \rightarrow \mathrm{N}_{2}^{2-}$, and taking into account the results from the theoretical calculations, one can assign to the $\mathrm{N}^{3-}$ ion the binding energy $B E_{1}=397.2 \mathrm{eV}$, as suggested in the literature; to the doubly charged molecular ion $\mathrm{N}_{2}^{2-}$ the peak at $B E_{2}=397.7 \mathrm{eV}$; and to the singly charged $\mathrm{N}_{2}^{-}$the peak at $B E_{3}=398.6 \mathrm{eV}$. The stability of the $\mathrm{N}_{2}^{-}$anion is also predicted by theoretical calculations in ref. 28 .

4.1.2 Current-voltage measurements-cathodic reduction. Concerning the rate limiting step of the reduction process, we estimate a Tafel slope for the cathodic reaction of $b_{1}=260 \mathrm{mV}$ $(2.3 \mathrm{RT} / \mathrm{F}=150 \mathrm{mV})$ evaluated from the experimental current voltage curve in region 1 . The value of the Tafel constant $b_{1}$ suggests a reduction process controlled by charge transfer with a transfer coefficient $\alpha=0.55$ assuming a single electron exchange step.

With diffusion limiting current of $I_{\mathrm{d}}=0.25 \mathrm{~mA}$ the diffusion coefficient of nitrogen has been estimated. According to eqn (5) the self diffusion coefficient for the nitride ions at $T=723 \mathrm{~K}$ is $D_{\mathrm{N}^{3-}}=2.6 \times 10^{-13} \mathrm{~m}^{2} \mathrm{~s}^{-1}$ calculated according to the equation:

$$
i_{d}=z \mathrm{~F} D_{i} \frac{c_{s}-c_{0}}{\delta}
$$

where $i_{\mathrm{d}}$ is the diffusion current density, $z$ is the total number of exchanged electrons, $\mathrm{F}$ is the Faraday constant, $D_{\mathrm{i}}$ the diffusion coefficient of the ions, $c_{s}$ and $c_{0}$ are the surface and volume concentrations of the nitride ions respectively and $\delta$ is the thickness of the diffusion layer. The value for $\delta$ was determined by the following procedure: We rapidly cooled the sample during cathodic polarization thus freezing the concentration profile. The surface and the volume concentrations have then been determined by SIMS analysis (depth profiles) using calibration standards with known nitrogen content prepared by ion implantation. The value for the diffusion layer thickness was $\delta=34 \mathrm{~nm}$. The nitrogen concentration dropped in this layer from approximately 18 at. $\%$ at the surface to 4 at. $\%$ (corresponding to the concentration in depth beneath the electrode).

4.1.3 Current-voltage measurements-anodic oxidation. The anodic process involving oxidation of nitrogen and/or oxide ions shows a typical passivation behaviour with a potential region of active oxidation, followed by a sharp 
decrease of the current due to a blocking effect at the active electrode surface. The Tafel slope in the active oxidation region (overvoltages of up to $\eta=0.6 \mathrm{~V}$ ) is too high to be assigned to a charge transfer limited process $-b_{2}=750 \mathrm{mV}$ and we conclude that the rate of the electrochemical reaction is determined by diffusion. In our experiments we cannot distinguish between oxidation of nitrogen and oxide ions, but because of the more negative electrode potential of the $\mathrm{N}^{3-} / \mathrm{N}_{2}$ redox couple we expect that firstly the nitrogen ions will be oxidized. However, because of the lower mobility of $\mathrm{N}^{3-}$ in the volume of the crystal ${ }^{13}$ and the much higher concentration of oxide ions the recorded currents are mainly due to the oxygen evolution reaction. We suggest that the passivation-like state at overvoltages above $0.6 \mathrm{~V}$ appears due to accumulation (adsorption) of product(s) of the reaction at the interface and not due to a formation of ion blocking $\operatorname{IrO}_{x}$ and/or insulating layers from impurities e.g. $\mathrm{SiO}_{2}$, because we cannot detect a chemical shift in the Ir $4 \mathrm{f}$ peak and no new $\mathrm{Si}$ peak can be detected. The passive state of the electrode disappears reversibly after switching the voltage off.

Because of the diffusion control of the anodic process, followed by deactivation of the electrode complete analysis concerning the mechanism of the nitrogen reaction based on the current voltage characteristics as provided in ref. 21 cannot be performed. We found, however, that the electrochemical reduction of dinitrogen involves two intermediate species with the formal charge of the (di)nitrogen ion being more positive than $\mathrm{N}^{3-}$ and with the process being controlled by the electron charge transfer.

\subsection{Oxygen 1s peak}

The oxygen electrode reaction and the position of $\mathrm{O} 1 \mathrm{~s}$ peak have been intensively studied on different oxide ion conducting solid electrolytes. However, because of the complexity of the electrochemical reaction different interpretation of the $\mathrm{O} 1 \mathrm{~s}$ XPS peaks were suggested. Even for non-polarized $\mathrm{ZrO}_{2}$ or YSZ samples the identification of the oxygen species is not unequivocally clarified. The reference binding energy of the $\mathrm{O}$ 1s peak in $\mathrm{ZrO}_{2}$ is reported to be $531.3 \mathrm{eV},{ }^{35}$ where additional oxygen species were suggested after deconvolution of the spectra at $532.70 \mathrm{eV}$ and $533.85 \mathrm{eV}$ but no specific chemical state for these has been proposed. It should be noted that the values for $\mathrm{O} 1 \mathrm{~s}$ peak binding energy in zirconia vary in the literature from $529.3 \mathrm{eV}^{44}$ up to $531.5 \mathrm{eV}^{45}$ where no deviation of the signal out of the given range was detected in YSZ compared to pure $\mathrm{ZrO}_{2}$. We reported previously a chemical shift of $1 \mathrm{eV}$ for the $\mathrm{O} 1 \mathrm{~s}$ binding energy in $\mathrm{ZrO}_{2}$ and YSZ. ${ }^{19}$

In YSZ single crystals Hughes reports on three different oxygen species representing lattice oxide ions, oxide ions beside an oxygen vacancy(ies) and adsorbed oxygen ions and/or hydroxyl species ${ }^{46}$ revealed after deconvolution of the O 1s signal. Ladas et al..$^{47}$ and Neophytides et al. ${ }^{48}$ also report on three different oxygen species during anodic polarization using YSZ electrolyte.

In our experiments we detect also three oxygen species: the peak at $B E_{1}=531.01 \mathrm{eV}$ we assign to the lattice oxide ions. For the signal at binding energy $B E_{2}=531.42 \mathrm{eV}$ we suggest to represent oxide ions adjacent to oxygen vacancies and the signal at $B E_{3}=532.59 \mathrm{eV}$ may represent adsorbed oxygen, ionic oxygen species, ${ }^{48}$ hydroxyl ions or oxide ions in $\mathrm{Y}_{2} \mathrm{O}_{3}$ (however no yttria phase was detected by XRD). We exclude from consideration oxygen species of the type $\mathrm{O}^{\delta-}(\delta<2)$ as reported in ref. 47 and 48, because the existence of stable, lower charged oxygen ions at highly negative working potentials is less probable.

Without applied voltage the main contribution to the total O 1s signal was of the species at $B E_{2}$ (see Table 5). It is known that due to higher internal energy of the surface atoms/ions their concentration can be vary compared to the "bulk"concentration. This is also valid for the contact surface between solid electrolyte and metal electrode, where defect concentrations may exceed few times the concentration in the volume. ${ }^{49}$ Thus, the strongest signal we detect is, we believe, due to surface oxide ions from the regular sublattice but bound stronger compared to the ions in the volume of the crystal. Also the contribution of the species at $B E_{3}$ (adsorbed species) is significant. Applying voltage the concentration of adsorbed species is reduced (the contribution of $B E_{3}$ strongly decreases) and $90 \%$ of the $\mathrm{O} 1 \mathrm{~s}$ peak is represented by $B E_{2}$. Decreasing the voltage further due to the difficulties in the mass transport through the three phase boundary (nitrogen diffusion limited current was observed and the effective concentration of nitrogen ions at the tpb strongly increases) the contribution of $B E_{2}$ decreases and the intensity of the peak at $B E_{1}$ increases, whereas the contribution of $B E_{3}$ remains low and constant. However, the detected types of oxide species are not directly related to the presence of nitrogen (or nitrogen ions) as our experiments in oxygen containing atmosphere have shown.

Moving away from the electrode the $\mathrm{O} 1 \mathrm{~s}$ peak position shifts towards higher binding energies (Fig. 7) and again the major contribution belongs to the oxygen species at $B E_{2}$.

\subsection{Electrochemical reduction of the YSZ electrolyte}

The second electrochemical process distinguished in Fig. 2 (region 2) is due to the electrochemical reduction of the YSZ electrolyte. It is of importance to study this process in order to understand in more details the electrochemical behaviour of the whole system during the cathodic polarization. The reduction of YSZ occurs as a concurrent process of the nitrogen reduction and is undesired, as it increases the electronic partial conductivity of the electrolyte and thus decreases the contribution of the ionic part. As the oxide ion in the lattice cannot be further reduced the new electronic states are expected to locate either at $\mathrm{Zr} 5 \mathrm{~s} / 4 \mathrm{~d}$ or $\mathrm{Y} 5 \mathrm{~s}$ or $4 \mathrm{~d}$ levels or alternatively at the levels provided by the oxygen vacancies forming $\mathrm{F}$ centers according to the electrode reactions:

$$
\mathrm{Zr}_{\mathrm{Zr}}^{\times}+z \mathrm{e}^{-} \rightleftharpoons \mathrm{Zr}_{\mathrm{Zr}}^{z^{\prime}} \text { or } \mathrm{Y}_{\mathrm{Zr}}^{\prime}+y \mathrm{e}^{-} \rightleftharpoons \mathrm{Y}_{\mathrm{Zr}}^{(y+1)^{\prime}}
$$

with $1 \leq z \leq 4 ; 1 \leq y \leq 3$ or alternatively

$$
\mathrm{V}_{\mathrm{O}}^{\bullet \bullet}+\mathrm{e}^{-} \rightleftharpoons \mathrm{V}_{\mathrm{O}}^{\bullet} \text { or } \mathrm{V}_{\mathrm{O}}^{\bullet \bullet}+2 \mathrm{e}^{-} \rightleftharpoons \mathrm{V}_{\mathrm{O}}^{\times}
$$

The incorporation of nitrogen ions also supports the increase of the number of electronic states providing energetically 
higher lying $2 \mathrm{p}$ levels and for non-stoichiometric substitution the band gap can be reduced up to $40 \% .^{11}$

In the literature numerous XPS studies on $\mathrm{Y}_{2} \mathrm{O}_{3}, \mathrm{ZrO}_{2}$ and YSZ have been published but only few deal with reduced zirconia. $^{50-53}$

4.3.1 Zr 3d peak. The XPS spectra of partially reduced zirconia reported in the literature cited above is characterized by additional $\mathrm{Zr} 3 \mathrm{~d}$ doublets at lower binding energies indicative of different zirconium ions with a charge formally given as $\mathrm{Zr}^{3+}\left(\mathrm{Zr}_{2} \mathrm{O}_{3}\right), \mathrm{Zr}^{2+}(\mathrm{ZrO}), \mathrm{Zr}^{+}\left(\mathrm{Zr}_{2} \mathrm{O}\right)$ and metallic zirconium. Steeb ${ }^{54}$ provides an overview of structures and chemical compositions of zirconium sub-oxides of the type $\mathrm{Zr}_{x} \mathrm{O}$ with $x=1-8$. However, these formal oxidation states are rather an indication for a different local coordination of the metal ion than refer to an actual charge transfer in the band structure. The exact identification of $\mathrm{Zr} \mathrm{3d}$ states in reduced zirconia cannot be done unambiguously as no reference standards are available, with the exception of the metal $\mathrm{Zr}$ and the completely oxidized zirconia $\left(\mathrm{ZrO}_{2}\right)$. Even here the reported values for the binding energies for $\mathrm{ZrO}_{2}$ or YSZ vary by up to $1 \mathrm{eV}$. In general the binding energy can shift either due to a change of the Madelung potential or due to a charge transfer. As the Madelung potential is structure specific one can expect a shift in the binding energy due to structure transitions of $\mathrm{ZrO}_{2}$ (monoclinic-tetragonal-cubic) induced by the dopant (i.e. $\mathrm{Ca}^{2+}, \mathrm{Y}^{3+}$ etc.). In addition the created oxygen vacancies may change locally the coordination number of $\mathrm{Zr}^{4+}$ ions, respectively the binding energy.

$\mathrm{Zr}^{+}$at $\mathrm{BE}_{1}=179.43 \mathrm{eV}$. Upon cathodic polarization no change in the shape or in the position in $\mathrm{Zr} 3 \mathrm{~d}$ peaks was detected at voltages of down to $-2 \mathrm{~V}$. At and below $E=-2 \mathrm{~V}$ the $\mathrm{Zr} 3 \mathrm{~d}$ peak splits into four doublets indicating reduction of the $\mathrm{Zr}$ initial formal oxidation state (Fig. 9). Based on the limited data in the existing literature we designate the peak $\mathrm{Zr} 3 \mathrm{~d}_{5 / 2}$ at $B E_{1}=179.43 \mathrm{eV}$ as $\mathrm{Zr}^{+}$ion corresponding to $\mathrm{Zr}_{x} \mathrm{O}$ with $x \geq 2$. We can exclude $\mathrm{Zr}$ metal formation as the chemical shift between $B E_{4}$ and $B E_{1}$ is $3.9 \mathrm{eV}$, whereas the lowest shift between $\mathrm{Zr}^{4+}$ and $\mathrm{Zr}^{0}$ state reported in the literature is $4.2 \mathrm{eV} .{ }^{52}$ In addition the binding energy of this peak is too high to be assigned to a metal state (typical $\left.E_{\mathrm{b}}=178.7 \mathrm{eV}\right) .{ }^{35}$ As it can be seen from Table 7 the intensity of this peak increases with the applied voltage with a maximum at $-2.5 \mathrm{~V}$.

$\mathrm{Zr}^{3+}$ for $\mathrm{ZrN}$ at $\mathrm{BE}_{2}=180.45 \mathrm{eV}$. The peak at binding energy $B E_{2}=180.45 \mathrm{eV}$ we attribute to the $\mathrm{Zr}^{3+}$ state in the $\mathrm{Zr}-\mathrm{N}$ bond. This suggestion is supported by the values for the binding energies for $\mathrm{ZrN}$ already reported in the literature where the lowest $E_{\mathrm{b}}$ for $\mathrm{Zr} 3 \mathrm{~d}_{5 / 2}$ in $\mathrm{ZrN}$ is $E_{\mathrm{b}}=179.6 \mathrm{eV}$ in ref. 55 and the highest one $E_{\mathrm{b}}=180.9 \mathrm{eV}$ is reported in ref. 56 However, varying the stoichiometry (i.e. nitrogen content) in $\mathrm{ZrN}_{x}$ from $x=0.18$ to 1.33 the $\mathrm{Zr} 3 \mathrm{~d}_{5 / 2}$ binding energies shift to higher values. In oxynitride $(\mathrm{Zr}-\mathrm{O}-\mathrm{N})$ systems which are closer to the chemical composition of our samples, for $\mathrm{Zr} 3 \mathrm{~d}_{5 / 2}$ values of up to $E_{\mathrm{b}}=182.2 \mathrm{eV}$ are reported. ${ }^{37}$ Thus we believe that the $\mathrm{N} 1 \mathrm{~s}$ peak at $B E_{2}$ is due to the $\mathrm{Zr}-\mathrm{N}$ bond. Moreover, in experiments at the same pressure and temperature but in oxygen atmosphere we cannot detect this peak. In experiments by Luerssen et al., mostly close to those in this work no $\mathrm{Zr} \mathrm{3d}$ peak at this binding energy was detected during electrochemical reduction of YSZ single crystal under high vacuum conditions. ${ }^{50}$

Decreasing the voltage from $-2 \mathrm{~V}$, where the peak area represents almost $50 \%$ from the total sum of all $\mathrm{Zr} 3 \mathrm{~d}$ peaks, to $-3 \mathrm{~V}$ we found a slight decrease in the relative peak area which we relate to a saturation of the nitrogen incorporation because not all of the nitrogen species electrochemically reduced at the three phase boundary can diffuse into the YSZ single crystal. In Fig. 2 the diffusion limited current of the nitrogen reaction can be found at applied voltages between $-1.7 \mathrm{~V}$ and $-2 \mathrm{~V}$. As the current is a measure for the reaction rate the diffusion current represents the maximum rate of nitrogen incorporation. At voltages below $E=-2 \mathrm{~V}$ the charge transfer process for the nitrogen reaction is faster and the diffusion of $\mathrm{N}^{3-}$ ions into the bulk becomes rate limiting. Additionally the concurrent process of electrolyte reduction starts and the further increase of the current at higher voltages is not related with the nitrogen reaction. As steady state conditions are assumed the number of nitrogen ions diffusing into YSZ should be time independent and thus the $\mathrm{Zr} 3 \mathrm{~d}$ peak accounting for $\mathrm{Zr}-\mathrm{N}$ bond also should not increase further and its relative component area should decrease.

$\mathrm{Zr}^{2+}$ at $\mathrm{BE}_{3}=181.4 \mathrm{eV}$. The $\mathrm{Zr} \mathrm{3d}$ doublet at binding energy $B E_{3}=181.4 \mathrm{eV}$ we designate to a formal oxidation state close to $\mathrm{Zr}^{2+}(\mathrm{ZrO})$. A peak at almost the same binding energy was reported by Luerssen et al. for electrochemically reduced YSZ. ${ }^{50}$ For pure $\mathrm{ZrO}_{2}$ the values for the binding energy of $\mathrm{Zr}^{2+}$ peak suggested by other authors reporting on oxidation of metal $\mathrm{Zr}$ are lower and deviate with up to $0.8 \mathrm{eV},{ }^{51,52}$ and the binding energy $E_{\mathrm{b}}=182 \mathrm{eV}$ of the $\mathrm{Zr} 3 \mathrm{~d}$ peak for $\mathrm{Zr}^{3+}$ state $\left(\mathrm{Zr}_{2} \mathrm{O}_{3}\right)$ reported in ref. 53 is too high. However, comparing our results for reduced YSZ with those from the literature the most reliable reference is ref. 50 because all other deal with oxidation of zirconium metal or $\mathrm{ZrN}$ and the exact values of the $\mathrm{Zr} 3 \mathrm{~d}$ peaks position may, as discussed above, vary.

$\mathrm{Zr}^{4+}$ at $\mathrm{BE}_{4}=183.3 \mathrm{eV}$. The binding energy of $\mathrm{Zr} \mathrm{3d}$ in YSZ reported in this work for a completely oxidized (non polarized) single crystal $\left(B E_{4}=183.3 \mathrm{eV}\right)$ is in agreement with our previous work on polycrystalline YSZ thin films and values given in the literature. ${ }^{19,53}$

As expected moving away from the electrode/electrolyte interface the intensity of the $\mathrm{Zr} 3 \mathrm{~d}$ peak components accounting for reduced species decreases and the contribution of the oxide component $\left(B E_{4}=183.33 \mathrm{eV}\right)$ increases, and becomes dominant but never the only one as in non polarized material (see Fig. 10).

4.3.2 Y 3d peak. The standard position of the binding energy for $\mathrm{Y} 3 \mathrm{~d}_{5 / 2}$ in $\mathrm{Y}_{2} \mathrm{O}_{3}$ and for metal $\mathrm{Y}$ is given in ref. 35 as $158.4 \mathrm{eV}$ and $155.7 \mathrm{eV}$, respectively. In YSZ the lowest reported binding energy for $\mathrm{Y} 3 \mathrm{~d}$ peak is $156.6 \mathrm{eV}^{44}$ and the highest is $158.9 \mathrm{eV},{ }^{19}$ and it has been found that the binding energy maximum does not depend on yttria content. ${ }^{19,44,57}$ To our knowledge literature on XPS studies of $\mathrm{Y} 3 \mathrm{~d}$ peak in reduced YSZ does not exist. 

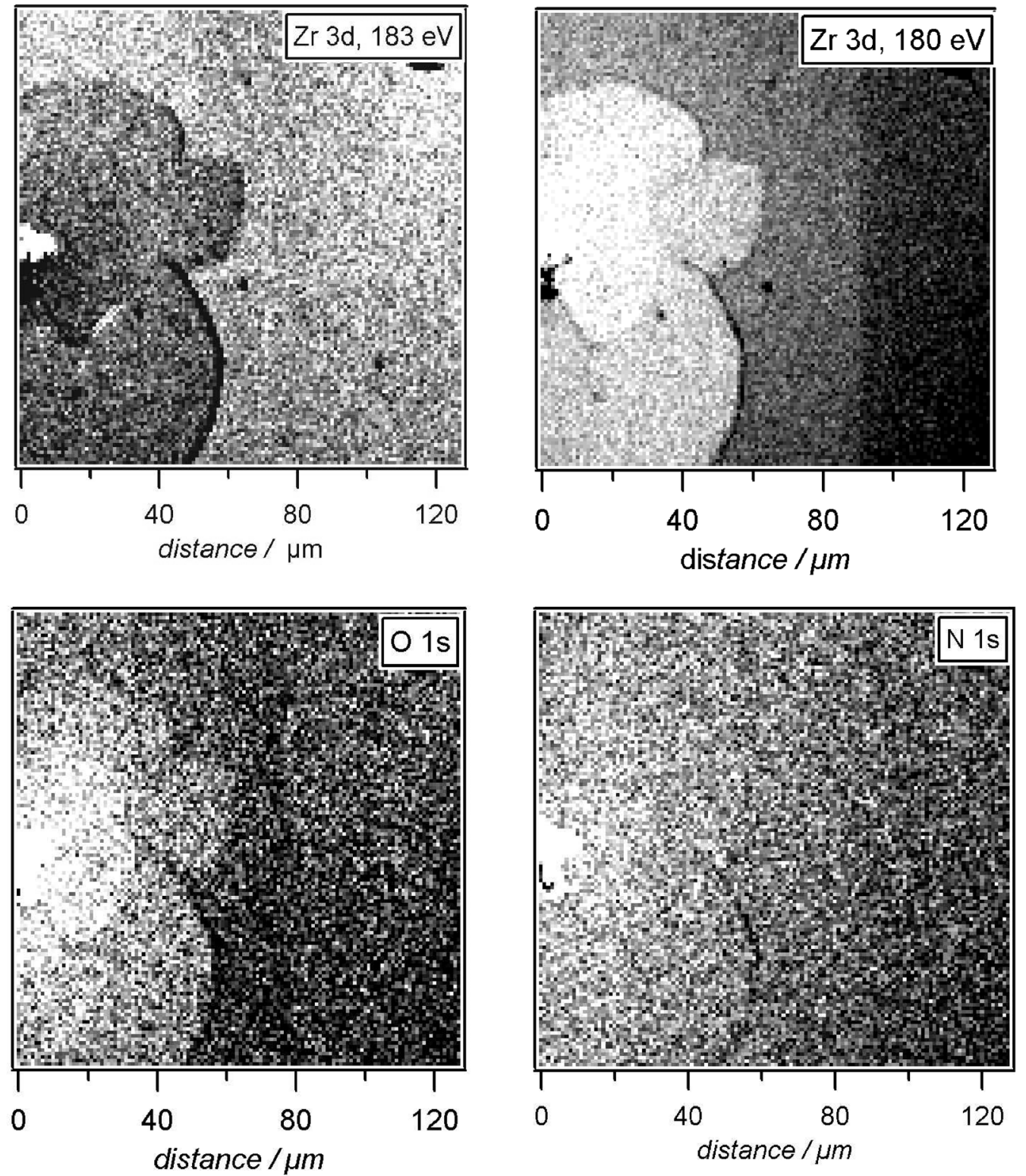

Fig. $14 \mathrm{Zr} 3 \mathrm{~d}, \mathrm{O} 1 \mathrm{~s}$ and $\mathrm{N} 1 \mathrm{~s}$ maps at iridium micro-electrode at $E=-3 \mathrm{~V}, p\left(\mathrm{~N}_{2}\right)=10^{-5} \mathrm{~Pa}, T=723 \mathrm{~K}$.

$Y^{3+}$ at $B E_{1}=158.3 \mathrm{eV}$. In our experiments on non polarized YSZ the binding energy for $\mathrm{Y} 3 \mathrm{~d}_{5 / 2}$ is $B E_{1}=$ $158.3 \mathrm{eV}$. This value remains unchanged also by applying a voltage of $-1.7 \mathrm{~V}$.

$$
Y^{x+}(0<\mathrm{x}<3) \text { at } B E_{2}=156.8 \mathrm{eV} \text {. At } E=-2 \mathrm{~V} \text { and }
$$
lower voltages a second doublet at $B E_{2}=156.8 \mathrm{eV}$ appears (Fig. 11). Its intensity increases by increasing the applied voltage and at $E=-3 \mathrm{~V}$ it is the dominating component. Two different suggestions for the origin of this peak can be found in the literature. De La Cruz observes binding energy for $\mathrm{Y} 3 \mathrm{~d}_{5 / 2}$ of $156.6 \mathrm{eV}$ in $\mathrm{YN}^{58}$ and Soto suggests the value of $156.2 \mathrm{eV} .^{40}$ However, exactly the same binding energy $(B E=156.6 \mathrm{eV})$ is reported from Majumdar for $\mathrm{Y} 3 \mathrm{~d}_{5 / 2}$ in YSZ. $^{44}$ Moreover in ref. 35 the deconvolution of $\mathrm{Y} 3 \mathrm{~d}$ spectrum for $\mathrm{Y}_{2} \mathrm{O}_{3}$ reveals beside the main $\mathrm{Y} 3 \mathrm{~d}_{5 / 2}$ peak at $158.4 \mathrm{eV}$ suboxide components with much lower binding energies where the lowest one was found at $155.9 \mathrm{eV}$. Thus, it is clear that the shift of the $\mathrm{Y} 3 \mathrm{~d}_{5 / 2}$ peak we recorded at $B E_{2}=156.8 \mathrm{eV}$ accounts for increased electronic density at the yttrium ion. We can definitely exclude metal formation, but we polarized YSZ single crystal in nitrogen free atmosphere (i.e. in oxygen) with $p=10^{-5} \mathrm{~Pa}$ and at applied voltages above $-2 \mathrm{~V}$ we clearly detect the $\mathrm{Y} 3 \mathrm{~d}$ component at $156.8 \mathrm{eV}$. Thus, we conclude that $B E_{2}=156.8 \mathrm{eV}$ appears due to yttria reduction and not due to nitrogen incorporation.

The intensity of the reduced component at $B E_{2}$ decreases with increasing distance from the $\mu$-electrode and at distance of $1500 \mu \mathrm{m}$ the main component (over $96 \%$ from the Y $3 \mathrm{~d}$ peak area) is the oxide component at $B E_{1}=158.3 \mathrm{eV}$.

\subsection{Electrochemical behaviour of $\mathrm{Pt} / \mathrm{YSZ} / \mathrm{Ir}\left(\mathrm{N}_{2}\right)$ cell}

After the discussion on the individual contributions of the two electrochemical processes the electrochemical behaviour of the 
whole system will be considered. Without applied voltage neither chemical reaction nor adsorption of nitrogen was detected on YSZ and at the iridium microelectrode. The calculated nonmetal/metal ratio of 2.3 is slightly higher than the expected value of 2 mainly because of surface adsorbates (moisture, rest oxygen etc.). Upon cathodic polarization the ratio remains 2 down to $E=-2 \mathrm{~V}$, and we assume that no electrolyte reduction takes place. The decrease of the ratio to $1.5 / 1.7$ at higher cathodic voltages is an indication for the initial state of reduction of the electrolyte. The subsequent impedance measurements we performed at $300 \mathrm{~K}$ and at $723 \mathrm{~K}$ show a completely insulating behaviour (at room temperature) and no increase of the total conductivity $(723 \mathrm{~K})$ which might be then attributed to enhanced electronic contribution.

The slight variation of the $\mathrm{Y} / \mathrm{Zr}$ ratio we relate to adsorption processes and not to a real change in the surface concentration, because a diffusion of these cations at this temperature can be practically excluded and the vapor pressure of the metal components is negligible.

The $\mathrm{N} / \mathrm{O}$ ratio at the electrode/electrolyte interface increases to a maximum value of 0.43 at $E=-3 \mathrm{~V}$ corresponding to 18 at.\% nitrogen in YSZ:N. The following SIMS analysis showed that in the volume of the YSZ single crystal (beneath the electrode) the nitrogen ion concentration was only 4 at.\%. This results confirms the limitation in the diffusion of nitride ions from the electrode/electrolyte interface into the volume, recorded also in the current-voltage measurements.

A complete chemical picture was obtained by using the SPEM imaging function recording the $\mathrm{N} 1 \mathrm{~s}, \mathrm{O} 1 \mathrm{~s}$ signal and as well for the contributions of reduced and oxidized $\mathrm{Zr} 3 \mathrm{~d}$ at and around the electrode/electrolyte contact. The intensity of the XPS peaks is presented as a colour intensity. In Fig. 14 can be seen that the contribution of the reduced part of $\mathrm{Zr} \mathrm{3d}$ (this includes the signals at $B E_{1}$ and $B E_{2}$ ) is dominating close to the electrode and moving away from the electrode the oxidized part becomes more significant. The $\mathrm{O} 1 \mathrm{~s}$ distribution does not indicate lower concentration i.e. significant reduction in the area around the iridium tip and nitrogen distribution is also homogeneous with decreasing intensity of $\mathrm{N}$ 1s signal increasing the distance to the electrode. Thus, we conclude that the incorporation of nitrogen ions is homogeneous and is not accompanied by significant electrolyte reduction.

The ex situ SIMS analysis shown in Fig. 13 confirmed the qualitative picture of nitrogen incorporation obtained by the XPS measurements. Nitrogen has been incorporated primarily under the electrode and the diffusion also occurred mainly under the electrode (Fig. $13 \mathrm{XZ}$ and $\mathrm{YZ}$ images) where the electric field was the strongest. However, nitrogen ions diffused also laterally as the whole experiment took approximately $90 \mathrm{~h}$.

\subsection{Formal treatment of the electrochemical process of nitrogen reduction}

Without applied voltage and constant temperature our system is at thermodynamic equilibrium and any flux of particles is assumed to be zero $\left(j_{i}=0\right)$. The linear flux equation for transport in YSZ is given by:

$$
j_{i}=-L_{i i} \cdot \nabla \tilde{\mu}_{i}=-\frac{D_{i} c_{i}}{R T} \cdot \nabla \tilde{\mu}_{i}
$$

where $i$ denotes different charge carriers $\left(\mathrm{e}^{-}, \mathrm{O}^{2-}, \mathrm{N}^{3-}\right), L_{i i}$ the diagonal phenomenological transport coefficient of particle $i$, and $c_{i}$ and $D_{i}$ represent the molar concentration and the self diffusion coefficient of the species $i$, respectively. If and when the particle flux is zero then the electrochemical potential gradient is also zero, i.e. $\nabla \tilde{\mu}_{i}=0$. As the concentration of oxide ions in YSZ is constant within a wide range of oxygen partial pressures there is no gradient in the chemical potential of $\mathrm{O}^{2-}$ ions $\left(\nabla \mu_{i}=0\right)$ and since $\tilde{\mu}_{i}=\mu_{i}+z_{i} F \phi$ the electrical potential gradient in the electrolyte is also zero $(\nabla \phi=0)$.

At equilibrium the open circuit potential is defined by the difference in the electrochemical potentials of electrons at both electrodes:

$$
-F E=\tilde{\mu}_{e^{\prime}}^{\prime \prime}-\tilde{\mu}_{e}^{\prime}
$$

Substituting eqn (3) for the both sides the measured voltage can be expressed as:

$$
F E=\frac{1}{2}\left(\tilde{\mu}_{\mathrm{O}^{2-}}^{\prime}-\tilde{\mu}_{\mathrm{O}^{2-}}^{\prime \prime}\right)-\frac{1}{4}\left(\tilde{\mu}_{\mathrm{O}_{2}}^{\prime}-\tilde{\mu}_{\mathrm{O}_{2}}^{\prime \prime}\right)=-\frac{R T}{4} \ln \frac{a_{\mathrm{O}_{2}}^{\prime}}{a_{\mathrm{O}_{2}}^{\prime \prime}}
$$

As stated above the flux is zero and respectively the electrical potential gradient and chemical potential gradient of oxide ions within the electrolyte is zero and $\nabla \tilde{\mu}_{\mathrm{O}^{2-}}=0$.

Thus, changing the oxygen activity we induce voltage or alternatively applying a voltage we change the $a_{\mathrm{O}_{2}}^{\prime} / a_{\mathrm{O}_{2}}^{\prime \prime}$ ratio once the ionic flux is blocked. Assuming that the $\mathrm{YSZ}$ volume is equilibrated at the counter electrode with the rest oxygen $\left(a_{\mathrm{O}_{2}}^{\prime}\right)$, and taking into account that high current densities are applied to the microelectrode in a nitrogen gas with negligible oxygen content, then the microelectrode acts as an oxygenblocking electrode. In this case, according to eqn (10) at temperature of $450{ }^{\circ} \mathrm{C}$ a $100 \mathrm{mV}$ increase of the applied voltage decreases the oxygen activity by more than two orders of magnitude. Once the cathodic polarisation voltage is large enough, the oxygen activity at the microelectrode is reduced to a sufficiently low value and molecular nitrogen is reduced at the electrode according to eqn (4). The cell voltage is then well described by a combination of the oxygen electrode at the counter electrode and the nitrogen half cell reaction at the microelectrode:

$$
F E=\frac{1}{2}\left(\tilde{\mu}_{\mathrm{O}^{2-}}^{\prime}-\frac{2}{3} \tilde{\mu}_{\mathrm{N}^{3-}}^{\prime \prime}\right)-\frac{1}{4}\left(\tilde{\mu}_{\mathrm{O}_{2}}^{\prime}-\frac{2}{3} \tilde{\mu}_{\mathrm{N}_{2}}^{\prime \prime}\right)
$$

Combining the standard terms of the chemical potentials and accounting that in the electrolyte $\nabla \phi=0$ we obtain:

$$
6 F E=-\sum_{i} \nu_{i} \mu_{i}^{\circ}-R T \ln \frac{\left(a_{\mathrm{O}^{2-}}^{\prime}\right)^{3} \cdot a_{\mathrm{N}_{2}}^{\prime \prime}}{\left(a_{\mathrm{O}_{2}}^{\prime}\right)^{3 / 2} \cdot\left(a_{\mathrm{N}^{3-}}^{\prime \prime}\right)^{2}}
$$

The schematic presentation of this process and qualitative evaluation of chemical/electrochemical potential change upon polarization is given in Fig. 15.

The local potential variation shown in Fig. 15 does not represent the system at an equilibrium state but a temporally limited steady state is assumed. In parts (a) to (d) the very initial state is depicted. The process of electrochemical nitrogen reduction is fully controlled by the charge transfer. However, the diffusion of $\mathrm{N}^{3-}$ into $\mathrm{YSZ}$ at this temperature is kinetically hindered and therefore the concentration of the 

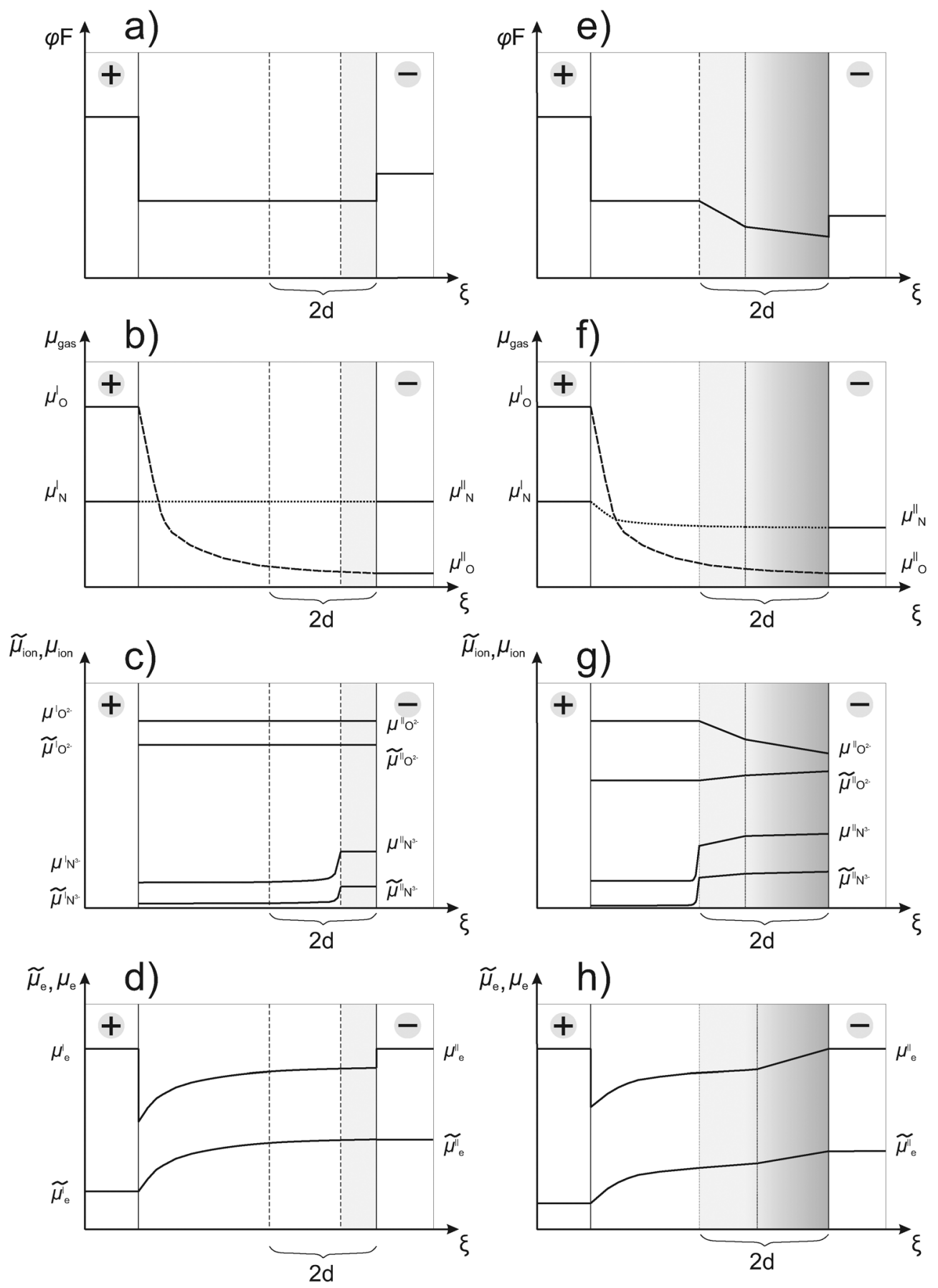

Fig. 15 Schematic presentation of the local potential variation during electrochemical reduction of nitrogen: (a-d) only nitrogen reduction process $(E<-2)$; (e-h) nitrogen reduction and reduction of YSZ.

incorporated nitrogen ions is negligible. Thus we assume a reversibility for the initial stage of the nitrogen reduction process, as also supported by XPS spectra at voltage of $E=-1.5 \mathrm{~V}$.

Comparing eqn (12) and reaction (1) one finds that the left side is the free formation enthalpy for reaction (1). Taking into account that the nitrogen pressure in the chamber was $10^{-5} \mathrm{~Pa}$, respectively oxygen partial pressure is $<10^{-9} \mathrm{~Pa}$ (oxygen content in $\mathrm{N}_{2}$ is below $50 \mathrm{ppm}$ given by the producer) the nitrogen reduction process starts at approximately $E=-1.25 \mathrm{~V}$ and thus the ratio between oxygen and nitrogen activities $k=a_{\mathrm{N}_{2}} / a_{\mathrm{O}_{2}}$ required for reaction (1) to proceed to the right at temperature of $723 \mathrm{~K}$ is estimated to be $k=5.2 \times 10^{46}$. The oxygen activity achieved at the micro-electrode is calculated to be $a_{\mathrm{O}_{2}}=1.4 \times 10^{-49}$, a value still approximately 20 orders of magnitude higher than the thermodynamic value for $\mathrm{ZrO}_{2}$ decomposition; we can therefore exclude reduction of zirconia. The calculated $a_{\mathrm{O}_{2}}$ value is the lowest limit of the oxygen activity because the micro-electrode was not encapsulated and the applied voltage may not exactly correspond to the oxygen 
activity calculated from eqn (10). However, as shown below the process of electrolyte reduction starts at a voltage, respectively oxygen activity, deviating by a factor of only 4 from the thermodynamic value, thus we confirm that eqn (10) used to calculate the oxygen activity at the iridium micro-electrode provides the correct values. Further we estimate the reaction free enthalpy (reaction (1)) and the equilibrium constant of the process at $T=723 \mathrm{~K}, \Delta_{r} G=$ $723.6 \mathrm{~kJ} \mathrm{~mol}^{-1}$ and $K_{\mathrm{a}}=5.2 \times 10^{-53}$, respectively.

Applying cathodic potentials lower than $E=-2 \mathrm{~V}$ the process of electrolyte reduction begins. The local potential variation is presented in Fig. 15(e-h). The nitrogen reduction reaction is limited by the rate of diffusion of nitrogen ions into the bulk (the diffusion limited current in Fig. 2). The diffusion limited current can be caused either by a slow diffusion of the end reaction product $\left(\mathrm{N}^{3-}\right)$ into the electrolyte volume or by a decrease of nitrogen partial pressure at the micro-electrode. The XPS spectra shown in Fig. 4 clearly demonstrates, that increasing the voltage the intensity of $\mathrm{N}$ 1s peak (nitrogen ion concentration) on the surface increases i.e. the limitation is caused by a slow diffusion into the bulk and not due to a decrease of nitrogen partial pressure. In order to electrochemically reduce the electrolyte oxygen activity must be reduced even further. At a cathodic potential of $E=-2 \mathrm{~V}$ the oxygen activity we estimated is $a_{\mathrm{O}_{2}}=1.7 \times 10^{-70}$. The theoretically calculated value for the decomposition of zirconia is $a_{\mathrm{O}_{2}}=6.8 \times 10^{-70}$ (data from) ${ }^{59}$ which gives a small difference by a factor of 4 and agrees relatively well. Diffusion of electrons into the YSZ volume is assumed as limiting factor in the process of electrolyte reduction.

\section{Conclusions}

We demonstrate by in situ XPS measurements during cathodic polarization, that molecular nitrogen can be electrochemically activated at the $\left(\mathrm{N}_{2}\right) \mathrm{Ir} / \mathrm{YSZ}$ three phase boundary. Nitrogen reduction is an electrochemical and not a chemical process starting at cathodic potentials still higher than these required for electrolyte reduction, i.e. nitrogen can be incorporated before the reduction of the electrolyte starts. Three different nitrogen species have been identified at the surface indicating a multi-step charge transfer process. Theoretical calculations support the reduction mechanism we suggest and indicate that the reduction of the nitrogen molecules proceeds through delocalized (Rydberg-type) electronic states.

At low overpotentials the charge transfer is rate limiting and at higher overvoltages it is the diffusion into the bulk. Nitrogen ions diffused into the YSZ single crystal both laterally and perpendicularly to the electrolyte surface.

By variation of the applied potential the Fermi level of the electrons shifts towards values sufficiently low to achieve the energy required for the nitrogen half cell reaction to proceed and therefore the free reaction enthalpy of oxygen substitution by nitrogen in YSZ was estimated.

We also demonstrate that $\mathrm{Zr}^{4+}, \mathrm{Y}^{3+}$ and $\mathrm{O}^{2-}$ ions are influenced by the applied voltage. However, neither zirconium nor yttrium ions have been completely reduced to metals but both $\mathrm{Zr} 3 \mathrm{~d}$ and $\mathrm{Y} 3 \mathrm{~d}$ peaks show signals at lower binding energies corresponding to a partially reduced oxidation states.
The deconvolution of the XPS spectra indicates the existence of four zirconium, two yttrium and three oxygen ionic species.

\section{Note added after first publication}

This article replaces the version published on 10th January 2011, which contained errors in eqn (9).

\section{References}

1 R. Aswahi, T. Morikawa, T. Ohwaki, K. Aoki and Y. Taga, Science, 2001, 293, 269-271.

2 M. Hara, G. Hitoki, T. Takata, J. N. Kondo, H. Kobayashi and K. Domen, Catal. Today, 2003, 78, 555-560.

3 T. Lindgrena, J. Lua, A. Hoela, C.-G. Granqvista, G. R. Torresb and S.-E. Lindquist, Sol. Energy Mater. Sol. Cells, 2004, 84, 145-157.

4 M. Jansen and H. P. Letschert, Nature, 2000, 404, 980-982.

5 E. Guenther and M. Jansen, Mater. Res. Bull., 2001, 36, 1399-1405.

6 M. Futsuhara, K. Yoshioka and O. Takai, Thin Solid Films, 1998, 317, 322-325.

7 J. Wendel, M. Lerch and W. Laqua, J. Solid State Chem., 1999, 142, 163-167.

8 M. Lerch, J. Janek, K. D. Becker, S. Berendts, H. Boysen, T. Bredow, R. Dronskowski, S. G. Ebbinghaus, M. Kilo, M. W. Lumey, M. Martin, C. Reimann, E. Schweda, I. Valov and H. D. Wiemhoefer, Prog. Solid State Chem., 2009, 37, 81-131.

9 M. Martin, R. Dronskowski, J. Janek, K.-D. Becker, D. Roehrens, J. Brendt, M. W. Lumey, L. Nagarajan, I. Valov and A. Boerger, Prog. Solid State Chem., 2009, 37, 132-152.

10 M. Kilo, M. A. Taylor, C. Argirusis, G. Borchardt, M. Lerch, O. Kaitasov and B. Lesage, Phys. Chem. Chem. Phys., 2004, 6, 3645-3649.

11 T. Bredow, Phys. Rev. B: Condens. Matter Mater. Phys., 2007, 75, 144102.

12 S. Gutzov and M. Lerch, Ceram. Int., 2007, 33, 147-150.

13 M. Taylor, M. Kilo, C. Argirusis, G. Borchardt, I. Valov, C. Korte, J. Janek, T. Roedel and M. Lerch, Defect Diffus. Forum, 2005, 237-240, 479-484.

14 J.-S. Lee, M. Lerch and J. Maier, J. Solid State Chem., 2006, 179(1), 270-277.

15 M. Lerch, J. Lerch and K. Lerch, J. Mater. Sci. Lett., 1996, 15 $2127-2129$.

16 M. Lerch and J. Lerch, J. Mater. Sci. Lett., 1997, 16, 1454-1456.

17 I. Valov, V. Rührup, R. Klein, T.-C. Rödel, A. Stork, S. Berendts, M. Dogan, H.-D. Wiemhöfer, M. Lerch and J. Janek, Solid State Ionics, 2009, 180, 1463-1470.

18 T.-C. Rödel, D. Wang, D. S. Su, M. Lerch, A. Prokofiev, K. D. Luther and W. Assmus, Cryst. Res. Technol., 2006, 41, 950.

19 I. Valov, R. A. D. Souza, C. Z. Wang, A. Börger, C. Korte, M. Martin, K.-D. Becker and J. Janek, J. Mater. Sci., 2007, 42, 1931-1941.

20 I. Valov, C. Korte, R. A. D. Souza, M. Martin and J. Janek, Electrochem. Solid-State Lett., 2006, 9, F23-F26.

21 I. Valov and J. Janek, Solid State Ionics, 2006, 177, 1619-1624.

22 A. Wilcockson and R. Casselton, J. Am. Ceram. Soc., 1970, 53, 293.

23 N. H. Nickel and M. A. Gluba, Phys. Rev. Lett., 2009, 103, 145501.

24 Y. Prots, G. Auffermann, M. Tovar and R. Kniep, Angew. Chem. Int. Ed., 2002, 41, 2288-2290.

25 G. Auffermann, U. Schmidt, B. Bayer, Y. Prots and R. Kniep, Anal. Bioanal. Chem., 2002, 373, 880-882.

26 D. L. Adams, FitXPS, University of Aarhus, Denmark, 2001, (http://www.sljus.lu.se/download.html).

27 S. Doniach and M. Sunjic, J. Phys. C: Solid State Phys., 1970, 3, 285-291.

28 C. Reimann and T. Bredow, THEOCHEM, 2009, 903, 89-99.

29 T. Bredow and A. R. Gerson, Phys. Rev. B: Condens. Matter Mater. Phys., 2000, 61, 5194-5201.

30 G. Zhang and C. B. Musgrave, J. Phys. Chem. A, 2007, 111, $1554-1561$.

31 A. R. Gerson and T. Bredow, Surf. Interface Anal., 2000, 29, $145-150$. 
32 M. Head-Gordon, R. J. Rico, M. Oumi and T. J. Lee, Chem. Phys. Lett., 1994, 219, 21-29.

33 M. J. Frisch, G. W. Trucks, H. B. Schlegel, G. E. Scuseria, M. A. Robb, J. R. Cheeseman, J. A. Montgomery, Jr., T. Vreven, K. N. Kudin, J. C. Burant, J. M. Millam, S. S. Iyengar, J. Tomasi, V. Barone, B. Mennucci, M. Cossi, G. Scalmani, N. Rega, G. A. Petersson, H. Nakatsuji, M. Hada, M. Ehara, K. Toyota, R. Fukuda, J. Hasegawa, M. Ishida, T. Nakajima, Y. Honda, O. Kitao, H. Nakai, M. Klene, X. Li, J. E. Knox, H. P. Hratchian, J. B. Cross, V. Bakken, C. Adamo, J. Jaramillo, R. Gomperts, R. E. Stratmann, O. Yazyev, A. J. Austin, R. Cammi, C. Pomelli, J. Ochterski, P. Y. Ayala, K. Morokuma, G. A. Voth, P. Salvador, J. J. Dannenberg, V. G. Zakrzewski, S. Dapprich, A. D. Daniels, M. C. Strain, O. Farkas, D. K. Malick, A. D. Rabuck, K. Raghavachari, J. B. Foresman, J. V. Ortiz, Q. Cui, A. G. Baboul, S. Clifford, J. Cioslowski, B. B. Stefanov, G. Liu, A. Liashenko, P. Piskorz, I. Komaromi, R. L. Martin, D. J. Fox, T. Keith, M. A. Al-Laham, C. Y. Peng, A. Nanayakkara, M. Challacombe, P. M. W. Gill, B. G. Johnson, W. Chen, M. W. Wong, C. Gonzalez and J. A. Pople, GAUSSIAN 03 (Revision C.02), Gaussian, Inc., Wallingford, CT, 2004.

34 A. B. Trofimov, T. E. Moskovskaya, E. V. Gromov, N. M. Vitkovskaya and J. Schirmer, J. Struct. Chem., 2000, 41, 483- 494.

35 B. V. Crist, Handbook of Monochromatic XPS Spectra: The Elements and Native Oxides, John Wiley \& Sons, Ltd, 2000.

36 M. D. Re, R. Gouttebaron, J.-P. Dauchot, P. Leclere, G. Terwagne and M. Hecq, Surf. Coat. Technol., 2003, 174-175, 240-245.

37 I. Milosev, H.-H. Strehblow, M. Gaberscek and B. Navinsek, Surf. Interface Anal., 1996, 24, 448-458.

38 I. Milosev, H.-H. Strehblow and B. Navinsek, Thin Solid Films, 1997, 303, 246-254.

39 P. Pietro, L. Galan and J. Sanz, Phys. Rev. B: Condens. Matter, 1993, 47, 1613-1615.
40 G. Soto, W. de la Cruz and M. Farias, J. Electron Spectrosc. Relat. Phenom., 2004, 135, 27-39.

41 C. T. Chen, Y. Ma and F. Sette, Phys. Rev. A: At., Mol., Opt. Phys., 1989, 40, 6737-6740.

42 L. L. Gendre, R. Marchand and Y. Laurent, J. Eur. Ceram. Soc., 1997, 17, 1813-1818.

43 H. Wiame, M.-A. Centeno, S. Picard, P. Bastians and P. Grange, J. Eur. Ceram. Soc., 1998, 18, 1293-1299.

44 D. Majumdar and D. Chatterjee, J. Appl. Phys., 1991, 70, 988-992.

45 D. Arias, Y. Arango and A. Devia, Appl. Surf. Sci., 2006, 253, 1683-1690.

46 A. E. Hughes, J. Am. Ceram. Soc., 2005, 78, 369-378.

47 S. Ladas, S. Kennou, S. Bebelis and C. G. Vayenas, J. Phys. Chem., 1993, 97, 8845-8848.

48 S. G. Neophytides, S. Zafeiratos and S. Kennou, Solid State Ionics, 2000, 136-137, 801-806.

49 V. Chebotin, I. Remez, L. Solovieva and S. Karpachev, Electrochim. Acta, 1984, 29, 1381-1388.

50 B. Luerßen, S. Guenther, H. Marbach, M. Kiskinova, J. Janek and R. Imbihl, Phys. Chem. Chem. Phys., 2002, 4, 2673-2679.

51 C. Morant, J. M. Sanz, L. Galan, L. Soriano and F. Rueda, Surf. Sci., 1989, 218, 331-345.

52 C. O. D. Gonzalez and E. A. Garcia, Surf. Sci., 1988, 193, 305-320.

53 L. Kumar, D. Sarma and S. Krummacher, Appl. Surf. Sci., 1988, 32, 309-319.

54 S. Steeb and A. Riekert, J. Less Common Met., 1969, 17, 429-436.

55 I. Bertoti, Surf. Coat. Technol., 2002, 151-152, 194-203.

56 S. Badrinarayanan, S. Sinha and A. Mandale, J. Electron Spectrosc. Relat. Phenom., 1989, 49, 303-309.

57 F. Parmigiani, L. Depero, L. Sangaletti and G. Samoggia, J. Electron Spectrosc. Relat. Phenom., 1993, 63, 1-10.

58 W. D. L. Cruz, J. Diaz, L. Mancera, N. Takeuchi and G. Soto, J. Phys. Chem. Solids, 2003, 64, 2273-2279.

59 I. Barin, Thermodynamical Data of Pure Substances, VCH-Weinheim, 1995. 